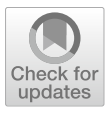

Cite as

Nano-Micro Lett.

(2022) 14:16

Received: 13 July 2021

Accepted: 27 September 2021

Published online: 6 December 2021

(C) The Author(s) 2021

\section{Directional Electromagnetic Interference Shielding Based on Step-Wise Asymmetric Conductive Networks}

\author{
Bai Xue ${ }^{1,2}, \mathrm{Yi} \mathrm{Li}^{1}$, Ziling Cheng ${ }^{1}$, Shengdu Yang ${ }^{1}$, Lan Xie ${ }^{1,2}$, Shuhao Qin ${ }^{2}$, \\ Qiang Zheng ${ }^{1,3,4} \bowtie$
}

\title{
HIGHLIGHTS
}

- Ni@MF/CNT/PBAT composites with step-wise asymmetric structures are fabricated via a facile solution encapsulation approach.

- The composites exhibit the unprecedented directional electromagnetic interference shielding performances $\left(\Delta \mathrm{SE} \mathrm{T}_{\mathrm{T}}=8.8 \mathrm{~dB}\right)$, which are further verified by an actual application measurement in a remote controlled toy car system.

\begin{abstract}
Some precision electronics such as signal transmitters need to not only emit effective signal but also be protected from the external electromagnetic (EM) waves. Thus, directional electromagnetic interference (EMI) shielding materials (i.e., when the EM wave is incident from different sides of the sample, the EMI shielding effectiveness (SE) is rather different) are strongly required; unfortunately, no comprehensive literature report is available on this research field. Herein, Nicoated melamine foams ( $\mathrm{Ni} @ \mathrm{MF}$ ) were obtained by a facile electroless plating process, and multiwalled carbon nanotube (CNT) papers were prepared via a simple vacuum-assisted self-assembly approach. Then, step-wise asymmetric poly(butylene adipate-co-terephthalate) (PBAT) composites consisting of loose Ni@MF layer and compact CNT layer
\end{abstract}

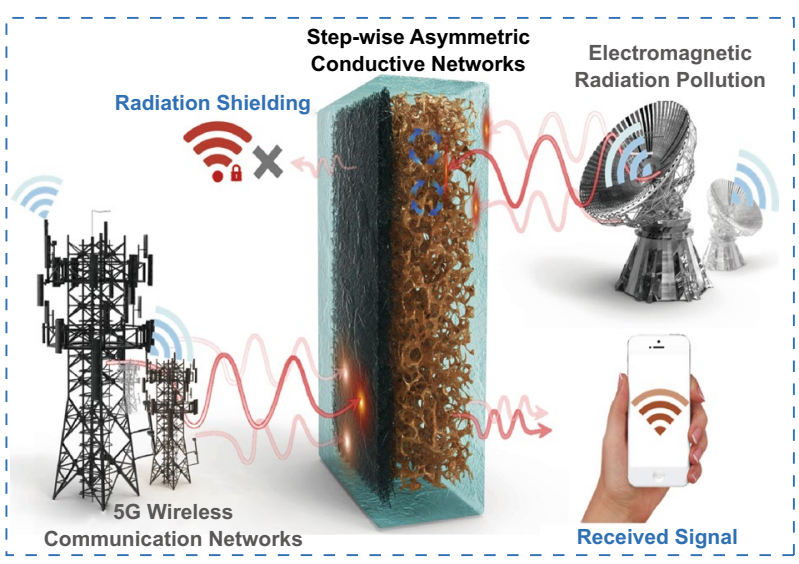
were successfully fabricated via a facile solution encapsulation approach. The step-wise asymmetric structures and electrical conductivity endow the Ni@MF/CNT/PBAT composites with unprecedented directional EMI shielding performances. When the EM wave is incident from Ni@MF layer or CNT layer, Ni@MF-5/CNT-75/PBAT exhibits the total EMI SE (SE T $_{\text {) }}$ of 38.3 and 29.5 dB, respectively, which illustrates the $\Delta \mathrm{SE}_{\mathrm{T}}$ of $8.8 \mathrm{~dB}$. This work opens a new research window for directional EMI shielding composites with step-wise asymmetric structures, which has promising applications in portable electronics and next-generation communication technologies.

KEYWORDS Solution encapsulation; Step-wise asymmetry; Directional electromagnetic interference shielding; Electrical conductivity; Vacuum-assisted self-assembly

\footnotetext{
$\square$ Lan Xie, mm.lanxie@gzu.edu.cn; Qiang Zheng, zhengqiang@zju.edu.cn

1 Department of Polymer Materials and Engineering, College of Materials and Metallurgy, Guizhou University, Guiyang 550025, People's Republic of China

2 National Engineering Research Center for Compounding and Modification of Polymer Materials, National and Local Joint Engineering Research Center for Functional Polymer Membrane Materials and Membrane Processes, Guiyang 550014, People's Republic of China

3 College of Polymer Science and Engineering, Zhejiang University, Hangzhou 310027, People's Republic of China

4 College of Materials Science and Engineering, Taiyuan University of Technology, Taiyuan 030024, People's Republic of China
} 


\section{Introduction}

Given the prosperity of electronic devices and modern telecommunication technology that are represented by newly emerged 5G wireless system, electromagnetic interference (EMI) pollution has become an inevitable and serious social issue that has greatly detrimental effects both on the operation of precision instruments and the health of human beings [1-4]. In order to attenuate undesirable electromagnetic (EM) wave, it is imperative and urgent to exploit high-performance EMI shielding materials [5-8]. Traditionally, metal-based materials are widely used in efficient EMI shielding because of the high conductivity and/or permeability, but intrinsic high density, easy corrosion, nonflexibility, and difficult processing make them less desirable for smart and subtle electronics [9-11]. As a consequence, it has created a crucial demand for developing new lightweight flexible EMI shielding materials with favorable mechanical properties.

In recent years, conductive polymer composites (CPCs) comprising polymer matrix and conductive fillers have drawn a wide of research interest and emerged as promising candidates in next-generation protection devices in terms of their superiorities such as light weight, low cost, flexibility, easy processing, and corrosion resistance [12-15]. Gu et al. [16] fabricated multifunctional flexible EMI shielding silver nanowires (AgNWs)/cellulose films via vacuum filtration and hot-pressing process. The AgNWs/cellulose film with $44.5 \mu \mathrm{m}$ exhibited superior EMI shielding effectiveness (SE) of $101 \mathrm{~dB}$, excellent thermal conductivity of $10.55 \mathrm{~W} \mathrm{mK}^{-1}$, and outstanding Joule heating performances at a $50 \mathrm{wt} \%$ loading fraction. As is well known, EMI SE of CPC materials is highly dependent on the electrical conductivity that could induce the enhancement of impedance mismatch and dielectric loss for EM wave. Thus, high filler content and/or sample thinness are fundamental to acquire ideal EMI SE of CPCs, leading to the reduction of flexibility, mechanical performances, and processability [17-19]. So, it remains a difficult task to develop high-efficient polymer-based EMI shielding materials with wonderful flexibility and mechanical properties.

As the structure of a material always determines its properties, structural design and controlling without sacrificing other merits are of great significance for realizing high-performance EMI shielding [20-24]. Recent researches have verified that various types of structures that are beneficial to EMI shielding are successfully constructed [25-29]. Therein, segregated structure is able to concentrate conductive fillers together to build conductive networks in polymer matrix, which accordingly reduces the conductive percolation threshold [30-34]. Li et al. [35] designed the segregated structure composed of magnetic hybrid ( $\mathrm{rGO} @ \mathrm{Fe}_{3} \mathrm{O}_{4}$ ) cores and CNT walls, which reached an EMI SE of $43.5 \mathrm{~dB}$ and $\mathrm{SE}_{\mathrm{A}} / \mathrm{SE}_{\mathrm{T}}$ ratio of $\sim 90 \%$ at $4 \mathrm{wt} \%$ $\mathrm{CNT} / 5 \mathrm{wt} \% \mathrm{rGO} @ \mathrm{Fe}_{3} \mathrm{O}_{4}$ loadings. Foam structure with a high porosity could not only lower the density but also greatly prolong the transmission path, enhancing the multiple reflection among cell walls and improving the EMI shielding ability [36-39]. Liang et al. [40] used woodderived porous carbon (WPC) skeleton as a template to construct ultralight 3D MXene aerogel/WPC composites, which exhibited excellent EMI shielding properties at quite low density $\left(71.3 \mathrm{~dB}, 0.197 \mathrm{~g} \mathrm{~cm}^{-3}\right)$. However, the issues of high thickness, poor mechanical properties, and weak flexibility are still existing. Inspired by the structure of nacre, the "brick-and-mortar" structure with superimposed layer toughening effects could impart the composites with excellent toughness and strength [41-45]. For instance, Shahzad et al. [43] prepared nacre-like MXene/sodium alginate (SA) via vacuum-assisted filtration beginning from colloidal solutions. The $8-\mu \mathrm{m}$-thick flexible MXene/ SA composite paper at $10 \mathrm{wt} \%$ SA content, in particular, exhibited extraordinary EMI SE of $57 \mathrm{~dB}$. Moreover, the research results of $\mathrm{Hu}$ et al. [46] confirmed layer-by-layer structures were effective to integrate the individual advantages of components. The sandwich structured film based on $\mathrm{Ca}$ ion cross-linked SA-montmorillonite (MMT) and $\mathrm{Ti}_{3} \mathrm{C}_{2} \mathrm{~T}_{x}$ MXene through step-by-step vacuum filtration simultaneously possessed effective EMI SE (50.01 dB), dramatically enhanced tensile strength (84.4 MPa), and fascinating fire resistivity.

However, along with the miniaturization and integration of modern electronics, some special components such as signal transmitters not only need to emit effective signal but also are protected from the external undesirable EM waves. Therefore, particular EMI shielding materials that are featured with different shielding performances, when EM waves are incident from different sides, are highly desirable for electronic devices. Latterly, gradient structures in asymmetric networks were extensively constructed to adjust the EMI 
shielding properties [47, 48]. Duan et al. [49] synthesized ordered multilayer gradient network composed of top hollow Ag-coated expanded polymer bead (EBAg) conductive shielding layer and bottom FeCo@rGO impedance matching layer. The EBAg/FeCo@rGO/WPU foams exhibited greatly slashed reflection coefficient $(R)$ when EM waves were incident from FeCo@rGO layer. However, nearly equal total EMI SE values $\left(\mathrm{SE}_{\mathrm{T}}\right)$ were obtained for the foams at different incident sides. The gradient structures are of great significance for controlling its contribution from absorption and reflection, rather than the $\mathrm{SE}_{\mathrm{T}}$. To date, no directional EMI shielding materials (i.e., the $\mathrm{SE}_{\mathrm{T}}$ is quite different, when the EM wave is incident from different sides of the sample) have been reported in the literature.

In this paper, Ni-coated melamine foam (Ni@MF)/multiwalled carbon nanotube (CNT)/Poly (butylene adipateco-terephthalate) (PBAT) composites with novel step-wise asymmetric structures were successfully fabricated via a facile solution encapsulation approach. Step-wise asymmetric $\mathrm{Ni@MF/CNT/PBAT} \mathrm{composites} \mathrm{composed} \mathrm{of} \mathrm{loose} \mathrm{porous}$ $\mathrm{Ni@MF}$ layer (top) and tight CNT layer (bottom) definitely exhibit distinctly asymmetric electrical conductivity on the top and bottom surfaces. The slightly conductive Ni@MF layer on the top of composites serves as an EM absorption layer; the highly conductive CNT layer on the bottom plays a role as an EM reflection layer. As expected, step-wise asymmetric Ni@MF-5/CNT-75/PBAT composites reveal the novel directional EMI shielding performance with an obvious $\Delta \mathrm{SE}_{\mathrm{T}}$ of $8.8 \mathrm{~dB}$. The directional EMI shielding of $\mathrm{Ni} @$ MF-5/CNT-75/PBAT composites is further confirmed by a practical application in a remote controlled toy car system. The step-wise asymmetric structure design strategy opens a new avenue for constructing and controlling directional EMI shielding materials for promising applications in nextgeneration communication technologies and smart intelligent electronics.

\section{Experimental Section}

\subsection{Materials}

Melamine foam (MF) sponges were purchased from Shanghai Beiyou Construction Materials Co., Ltd., China. Tin (II) chloride $\left(\mathrm{SnCl}_{2} \cdot 2 \mathrm{H}_{2} \mathrm{O}\right)$, nickel chloride $\left(\mathrm{NiCl}_{2} \cdot 6 \mathrm{H}_{2} \mathrm{O}\right)$, sodium citrate $\left(\mathrm{C}_{6} \mathrm{H}_{5} \mathrm{Na}_{3} \mathrm{O}_{7} \cdot 2 \mathrm{H}_{2} \mathrm{O}\right)$, sodium hypophosphite
$\left(\mathrm{NaH}_{2} \mathrm{PO}_{2}\right)$, ammonium hydroxide $\left(\mathrm{NH}_{3} \cdot \mathrm{H}_{2} \mathrm{O}\right)$, and polyethylene oxide (PEO, $\overline{M_{\mathrm{v}}} \approx 1.0 \times 10^{6} \mathrm{~g} \mathrm{~mol}^{-1}$ ) were procured from Macklin Biochemical Co., Ltd., Shanghai, China. Palladium (II) chloride $\left(\mathrm{PdCl}_{2}\right)$ was obtained from Sinopharm Chemical Reagent Co., Ltd., China. Hydrochloric acid ( $\mathrm{HCl}, 37 \mathrm{wt} \%$ ) was acquired from Chongqing Chuandong Chemical Co., Ltd., China. Multiwalled carbon nanotube (CNT, $>90 \%$ ) with an external diameter of 10-20 nm and a length of $<30 \mu \mathrm{m}$ was provided by Chengdu Organic Chemicals Co., Ltd., China. Dichloromethane $\left(\mathrm{CH}_{2} \mathrm{Cl}_{2},>99.5 \%\right)$ was supplied by Tianjin Fuyu Fine Chemical Co., Ltd., China. Poly (butylene adipate-co-terephthalate) (PBAT) with a density of $1.21 \mathrm{~g} \mathrm{~cm}^{-3}$ and $\overline{M_{\mathrm{w}}}=1.42 \times 10^{5} \mathrm{~g} \mathrm{~mol}^{-1}$ was achieved from Xinjiang Blue Ridge Tunhe Chemical Industry Joint Stock Co., Ltd., China.

\subsection{Preparation of Ni-Plated MF Sponges (Ni@MF)}

Ni-plated MF sponges were prepared via a facile electroless plating process. Typically, commercially available MF sponges were cut into the dimension of $3.5 \times 2.0 \times 0.2 \mathrm{~cm}^{3}$ and cleaned with water in an ultrasonic washer for 3 times. Afterward, the MF sponges were sensitized in a $100 \mathrm{~mL}$ $2 \mathrm{wt} \% \mathrm{SnCl}_{2} / 0.37 \mathrm{wt} \% \mathrm{HCl}$ aqueous solution under ultrasonication for $30 \mathrm{~min}$. The sensitized MF sponges were subsequently activated in a $100 \mathrm{~mL}$ activation solution comprising $10 \mathrm{mg} \mathrm{PdCl}$ and $0.1 \mathrm{~mL} \mathrm{HCl}$ at ultrasonic treatment for $30 \mathrm{~min}$. The activated MF sponges were rinsed with plenty of distilled water and dried. Then, $2 \mathrm{~g} \mathrm{NiCl}_{2}, 3 \mathrm{~g} \mathrm{C}_{6} \mathrm{H}_{5} \mathrm{Na}_{3} \mathrm{O}_{7}$, and $12 \mathrm{~mL} \mathrm{NH}_{3} \cdot \mathrm{H}_{2} \mathrm{O}$ were dissolved into $90 \mathrm{~mL}$ deionized water to obtain the nickel-plating bath solution. The treated MF sponges were immersed in the plating bath, and a reducing agent $\left(10 \mathrm{~mL} 40 \mathrm{wt} \% \mathrm{NaH}_{2} \mathrm{PO}_{2}\right.$ water solution) was added into the bath drop by drop with vigorous mechanical stirring at $50{ }^{\circ} \mathrm{C}$. After a certain amount of plating time, the $\mathrm{Ni} @ \mathrm{MF}$ sponges were washed with distilled water and dried in a vacuum oven at $40^{\circ} \mathrm{C}$.

\subsection{Fabrication of CNT Papers}

A facile vacuum-assisted self-assembly approach was proposed to fabricate CNT papers. In a typical procedure, $20 \mathrm{mg}$ of PEO was dissolved into $200 \mathrm{~mL}$ deionized water with continuous stirring, and then, $200 \mathrm{mg}$ CNT was dispersed 
into the obtained PEO solution under ultrasonication for $20 \mathrm{~min}$. Thereafter, a certain quantity of CNT suspension was filtered in a vacuum by a cellulose acetate filter membrane with a diameter of $47 \mathrm{~mm}$ and pore size of $0.22 \mu \mathrm{m}$. Finally, CNT papers were peeled off from the filter membranes after drying at room temperature overnight. A series of CNT papers with different thicknesses of $25,50,75$, and $100 \mu \mathrm{m}$ were successfully fabricated via controlling the quantity of CNT suspension.

\subsection{Fabrication of Ni@MF/CNT/PBAT Composites}

The Ni@MF/CNT/PBAT composites were manufactured by simple solution encapsulation. Firstly, $4 \mathrm{~g}$ of PBAT was dissolved into $10 \mathrm{~mL} \mathrm{CH}_{2} \mathrm{Cl}_{2}$ under vigorous agitation, followed by degassing and casting into a culture dish. Afterward, Ni@MF and CNT paper were together immersed into the PBAT $\mathrm{CH}_{2} \mathrm{Cl}_{2}$ solution, where CNT paper was situated beneath $\mathrm{Ni@MF.} \mathrm{The} \mathrm{culture} \mathrm{dish} \mathrm{was} \mathrm{transferred} \mathrm{in} \mathrm{an} \mathrm{oven}$ at $60{ }^{\circ} \mathrm{C}$ for $12 \mathrm{~h}$ to evaporate the solvent, and $\mathrm{Ni} @ \mathrm{MF} / \mathrm{CNT} /$ PBAT composites were finally obtained. For brevity, the prepared Ni@MF/CNT/PBAT composites were labeled as Ni@ MF- $x /$ CNT- $y /$ PBAT, where $x$ represents the nickel-plating time for Ni@MF (min) and $y$ denotes the thickness of CNT paper $(\mu \mathrm{m})$. In addition, the thickness of all the samples is $1.8 \mathrm{~mm}$ after tailoring.

\subsection{Characterizations}

The morphology and microstructures of Ni@MF, CNT papers, and Ni@MF/CNT/PBAT composites were observed on field emission scanning electron microscope (FESEM, Hitachi SU8010, Japan). Energy-dispersive spectrum (EDS) mappings were applied to determine the distribution of Ni element in Ni@MF and composites. So as to investigate the crystalline structures, X-ray diffraction (XRD) patterns were recorded on a PANalytical diffractometer (the Netherlands) with $\mathrm{Cu} \mathrm{K} \alpha$ radiation $(\lambda=1.5406 \AA)$ in the range from $5^{\circ}$ to $90^{\circ}$. The surface element states of samples were estimated by using an X-ray photoelectron spectrometer (XPS, Escalab 250XI, Thermo Fisher Scientific, USA). The volume resistivity of composites was tested using a four-point probe resistivity determiner (Signatone, USA). The probe was penetrated into the CNT layer or Ni@MF layer of Ni@MF/CNT/ PBAT composites during the measurement. A vector network analyzer (VNA, N5244A, Agilent Technologies, USA) was employed to detect the electromagnetic interference (EMI) shielding effectiveness (SE) of such composites over the X-band $(8.2-12.4 \mathrm{GHz})$. From the scattering parameters, $S_{11}$ and $S_{21}$, the power coefficient of transmissivity (T), absorptivity (A), and reflectivity (R), the total EMI SE ( $\left.\mathrm{SE}_{\mathrm{T}}\right)$, reflection EMI SE $\left(\mathrm{SE}_{\mathrm{R}}\right)$, and absorption EMI SE $\left(\mathrm{SE}_{\mathrm{A}}\right)$ were calculated by Eqs. $(1-8)[15,50]$ :

$R=\left|S_{11}\right|^{2}$ and $T=\left|S_{21}\right|^{2}$

$A=1-(T+R)$

$\mathrm{SE}_{\mathrm{T}}=10 \log \frac{1}{T}$

$\mathrm{SE}_{\mathrm{R}}=10 \log \left(\frac{1}{1-R}\right)$

$\mathrm{SE}_{\mathrm{A}}=10 \log \left(\frac{1-R}{T}\right)$

$\mathrm{SE}_{\mathrm{T}}=\mathrm{SE}_{\mathrm{R}}+\mathrm{SE}_{\mathrm{A}}+\mathrm{SE}_{\mathrm{M}}$

$\mathrm{SE}_{\mathrm{T}}=\left|\mathrm{SE}_{\mathrm{T} 1}-\mathrm{SE}_{\mathrm{T} 2}\right|$

SE enhancement $=\Delta \mathrm{SE}_{\mathrm{T}} / \mathrm{SE}_{\mathrm{T} 2}$

where "1" and "2" denote that the EM wave is incident from $\mathrm{Ni} @ \mathrm{MF}$ layer and CNT layer, respectively.

When $\mathrm{SE}_{\mathrm{T}}$ is greater than $15 \mathrm{~dB}, \mathrm{SE}_{\mathrm{M}}$ could be usually ignored. Tensile measurement was conducted on a universal testing machine (Model 5576, Instron, USA) with a loading rate of $1 \mathrm{~mm} \mathrm{~min}^{-1}$ at ambient temperature.

\section{Results and Discussion}

\subsection{Fabrication of Step-Wise Asymmetric Conductive Networks}

The meaningful design of step-wise asymmetric Ni@ $\mathrm{MF} / \mathrm{CNT} / \mathrm{PBAT}$ composites involves the vacuum-assisted 
self-assembly of CNT paper, electroless Ni plating for MF, and their integrated encapsulation in PBAT dichloromethane solution (Figs. 1a and S1). During the vacuum-assisted filtration process of CNT paper, a bit of polyethylene oxide (PEO), which is water-soluble, environmentally benign, as well as compatible with CNT, is specially introduced to cohere neighbor CNTs, guaranteeing excellent compactibility of CNT paper. Thus, CNT paper definitely exhibits the pretty aligned lamellar microstructures along in-plane direction with slight undulation, on account of the intense interaction between CNTs and PEO such as hydrogen bonds (Fig. 1b). CNTs are compactly stacked and entangled together to build the tight connected conductive network during the vacuum filtration, contributing to the superior electrical conductivity of CNT paper $[50,51]$. SEM images of pure MF reveal that MF sponge possesses a perfect $3 \mathrm{D}$ porous structure (Fig. S2a) and the surface of MF skeleton is quite smooth without any protrusion (Fig. 1c). After 5 min of Ni plating, Ni@MF-5 exhibits a rough skeleton surface (Fig. 1d) and tiny $\mathrm{Ni}$ (a) Melamine Foam (MF)
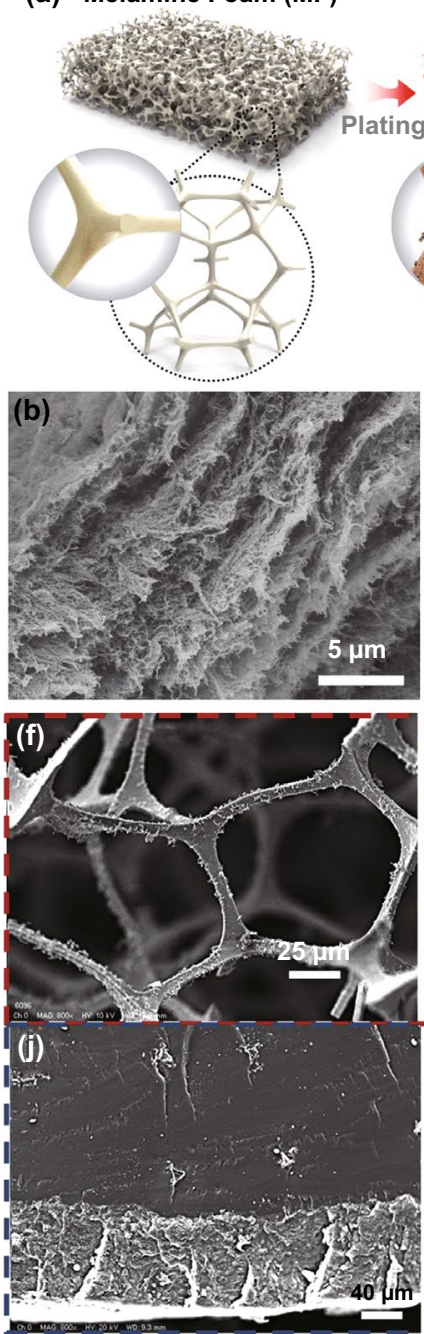
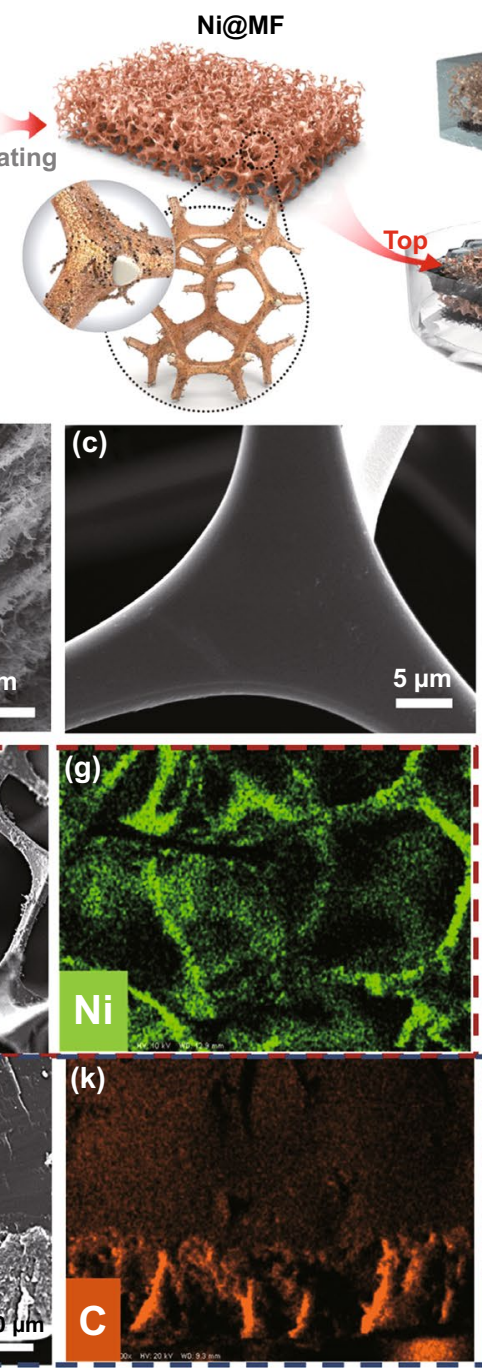

Ni@MF/CNT/PBAT
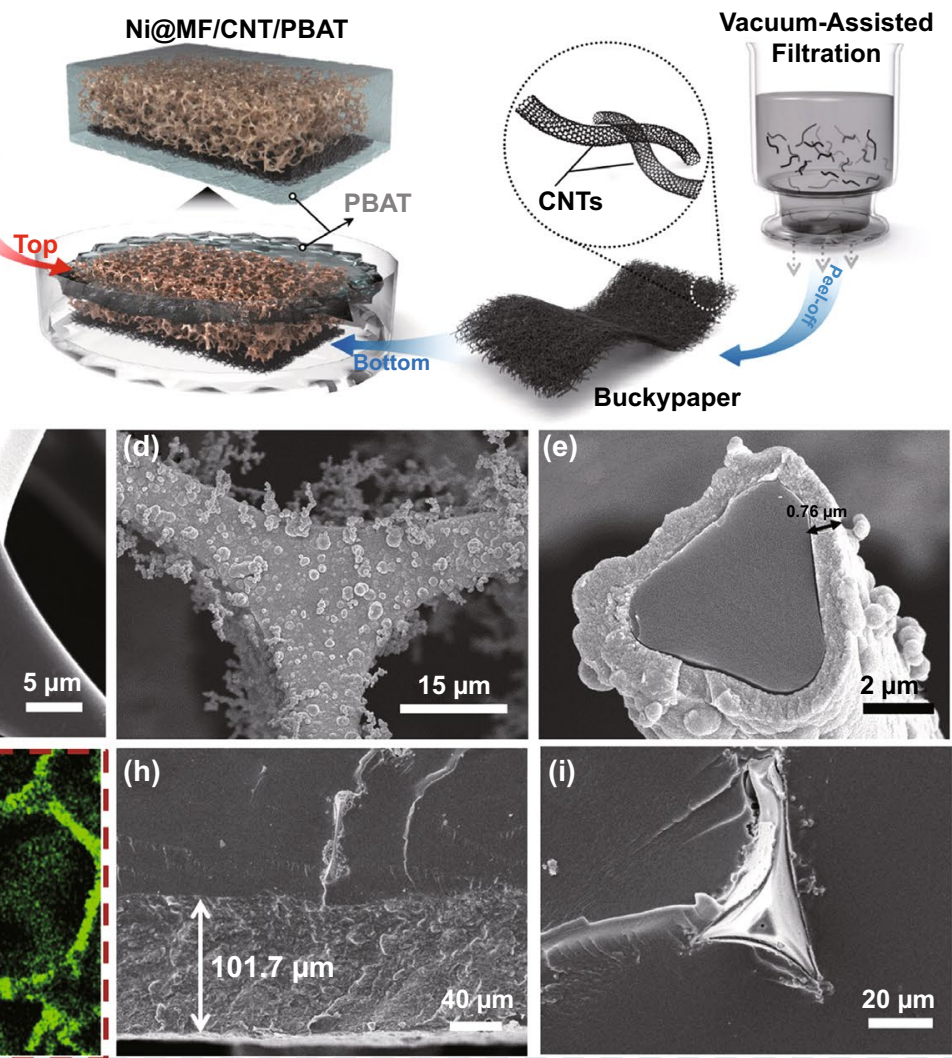

(i)
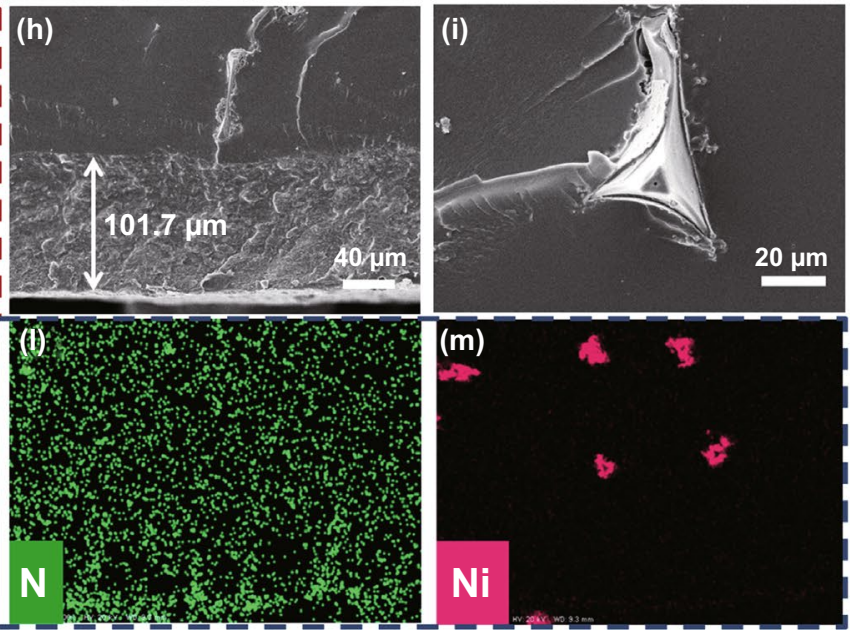

Fig. 1 Fabrication of step-wise asymmetric Ni@MF/CNT/PBAT composites. a Schematic diagram for the preparation process of step-wise asymmetric Ni@MF/CNT/PBAT composites. b and c SEM images of CNT paper and pure MF sponge, respectively. d and e SEM images of Ni@MF-5 at different magnifications, where 5 represents the Ni-plating time of 5 min. $\mathbf{f}$ and $\mathbf{g}$ SEM of Ni@ MF-5 with Ni elemental EDS mapping. h SEM image of the lower CNT-75/PBAT layer in Ni@MF-5/CNT-75/PBAT, where 75 denotes the thickness of CNT paper ( $\mu$ m). i SEM image of the upper Ni@MF-5/PBAT layer. j-m SEM of Ni@MF-5/CNT-75/PBAT with C, N, Ni elemental EDS mappings 
particles are tightly clustered together to form a uniform Ni layer of $0.76 \mu \mathrm{m}$ thickness (Figs. 1e and S3), whereas the 3D porous structure is well remained (Fig. S2b). Furthermore, SEM of Ni@MF-5 with Ni elemental EDS mapping (Fig. 1f, g) illuminates that Ni element is mainly selectively distributed on the MF cell walls, further confirming the successful electroless plating of Ni particles. The morphology of Ni@MF is greatly dependent on the plating time. Generally, more Ni particles are deposited on the MF skeleton and the increasingly tough surface is consequently obtained with the prolonged plating time (Fig. S4). The loading of Ni layer is gradually elevated from $22.1 \mathrm{wt} \%$ for $1 \mathrm{~min}$ plating time to $73.9 \mathrm{wt} \%$ for 5 min plating time (Fig. S5). These results certainly illustrate that compact CNT paper and loose Ni@MF with superb conductive networks are successfully yielded.

Afterward, CNT paper and Ni@MF are impregnated together into PBAT dichloromethane solution to fabricate step-wise asymmetric Ni@MF/CNT/PBAT composites. Ni@MF-5/CNT-75/PBAT (Ni@MF- $x$ /CNT- $y$ /PBAT: $x$ is the plating time ( $\mathrm{min})$, and $y$ represents the thickness of CNT paper $(\mu \mathrm{m})$ ) displays the evident step-wise layered structures (Fig. 1h). The fracture surface of the upper Ni@MF-5/PBAT layer is a lot smoother, except some MF skeleton protrusions are exposed (Fig. 1i). However, a much rougher fracture surface is clearly observed for the lower CNT-75/PBAT layer with a thickness around $101.7 \mu \mathrm{m}$ which is higher than that of CNT paper before impregnation (Fig. 1h). The EDS mappings of the sample can help in validating the construction of step-wise asymmetric networks (Fig. 1j-m). The C element is more densely distributed in lower CNT/PBAT layer, while the distribution of $\mathrm{Ni}$ element is merely accumulated at the exposed $\mathrm{Ni@MF} \mathrm{skeletons} \mathrm{in} \mathrm{upper} \mathrm{Ni@}$ MF/PBAT layer. For various Ni@MF foams with different plating times, Ni@MF/CNT/PBAT composites can be all facilely prepared, and the plating time has little impact on the step-wise asymmetric structure (Fig. S6). Besides, Ni@ MF/CNT/PBAT composites with different thicknesses of CNT paper also exhibit the unique step-wise asymmetric structure (Fig. S7). The thickness of the lower CNT/PBAT layer is continuously increased with the incremental thickness of CNT paper, ranging from $25.2 \mu \mathrm{m}$ for Ni@MF-3/ CNT-25/PBAT to $127.1 \mu \mathrm{m}$ for Ni@MF-3/CNT-100/PBAT (Fig. S8). Hence, the step-wise asymmetric structure is able to be adjusted to some extent by changing the fabrication condition.

\subsection{Structures of Ni@MF/CNT/PBAT Composites}

XRD analysis is employed to determine the phase of composite structures. It is conspicuously found that MF as an uncrystallized polymer exhibits a typical amorphous XRD pattern (Fig. 2a). After the plating of Ni, the visible characteristic diffraction peak for Ni@MF-5 at $44.5^{\circ}$ is assigned to the (111) plane of face-centered cubic phase $\mathrm{Ni}$, illustrating that wellcrystallized FCC Ni nanoparticles are formed on the pore wall of MF sponges (Fig. 2a). Two conspicuous diffraction peaks observed at $26.6^{\circ}$ and $42.6^{\circ}$ in CNT XRD curve are indexed to (002) and (100) lattice planes of CNT crystalline structures, respectively. Besides, a new moderate peak is located at $19.2^{\circ}$ for CNF/PEO paper, corresponding to the (120) plane of PEO. PBAT, a semi-crystalline polymer, exhibits the four strong peaks at $16.3^{\circ}, 17.4^{\circ}, 20.2^{\circ}$, and $23.1^{\circ}$, which is in accord with (011), (010), (110), and (100) lattice planes of PBAT crystals (Figs. $2 \mathrm{~b}$ and S9). Strikingly, all the above featured peaks are also clearly traced in the XRD pattern of Ni@MF-5/CNT-75/ PBAT, which indicates that the encapsulation has little effect on the crystal structures of the constituents (Fig. 2b).

The chemical composition and surface element state of Ni@MF-5 are detected by XPS characterization. The full XPS pattern of pure MF manifests the existence of C, $\mathrm{N}$, and $\mathrm{O}$ elements, whereas the survey spectrum of $\mathrm{Ni@}$ MF-5 reveals the successful deposition of zero-valent $\mathrm{Ni}$ (Fig. 2c and Table S1). The characteristic peaks corresponding to Ni2 $\mathrm{p}_{1 / 2}, \mathrm{Ni} 2 \mathrm{p}_{3 / 2}, \mathrm{Ni} 3 \mathrm{~s}$, and Ni $3 \mathrm{p}$ are detailedly located at the binding energy of 872.1,855.3, 112.5, and $67.5 \mathrm{eV}$, respectively. The N $1 \mathrm{~s}$ core-level peaks of both MF and Ni@MF-5 are centered at 398.8 eV; however, the peak width is intuitionally raised with the conversion plating of Ni (Fig. 2d), which signifies the excellent interaction between MF and Ni particles. In the high-resolution C $1 \mathrm{~s}$ XPS spectra (Fig. 2e), four major feature peaks situated at 289.2, 287.6, 286.5, and $284.8 \mathrm{eV}$ for both $\mathrm{MF}$ and $\mathrm{Ni} @ \mathrm{MF}-5$ are attributed to $-\mathrm{C}=\mathrm{O}, \mathrm{C}=\mathrm{N}, \mathrm{C}-\mathrm{O}$, and $\mathrm{C}-\mathrm{C}$, respectively. Therefore, the chemical structures of $\mathrm{MF}$ are well reserved after the electroless plating of Ni. The $\mathrm{Ni} 2 \mathrm{p}$ core-level spectrum of Ni@MF-5 can be appropriately fitted with two types ( $\mathrm{Ni} 2 \mathrm{p}_{1 / 2}$ and $\mathrm{Ni} 2 \mathrm{p}_{3 / 2}$, Fig. 2f), which is consistent with the results of Fig. 2c. In detail, $\mathrm{Ni} 2 \mathrm{p}_{1 / 2}$ at $873.5 \mathrm{eV}$ and $\mathrm{Ni} 2 \mathrm{p}_{3 / 2}$ at $852.7 \mathrm{eV}$ are ascribed to metallic $\mathrm{Ni}\left(\mathrm{Ni}^{0}\right)$, indicating that some $\mathrm{Ni}^{2+}$ ions have been reduced to $\mathrm{Ni}^{0}$ valence state during the $\mathrm{Ni}$ plating. Furthermore, Ni $2 \mathrm{p}_{1 / 2}$ at $881.6-878.8 \mathrm{eV}$ and $\mathrm{Ni} 2 \mathrm{p}_{3 / 2}$ at 

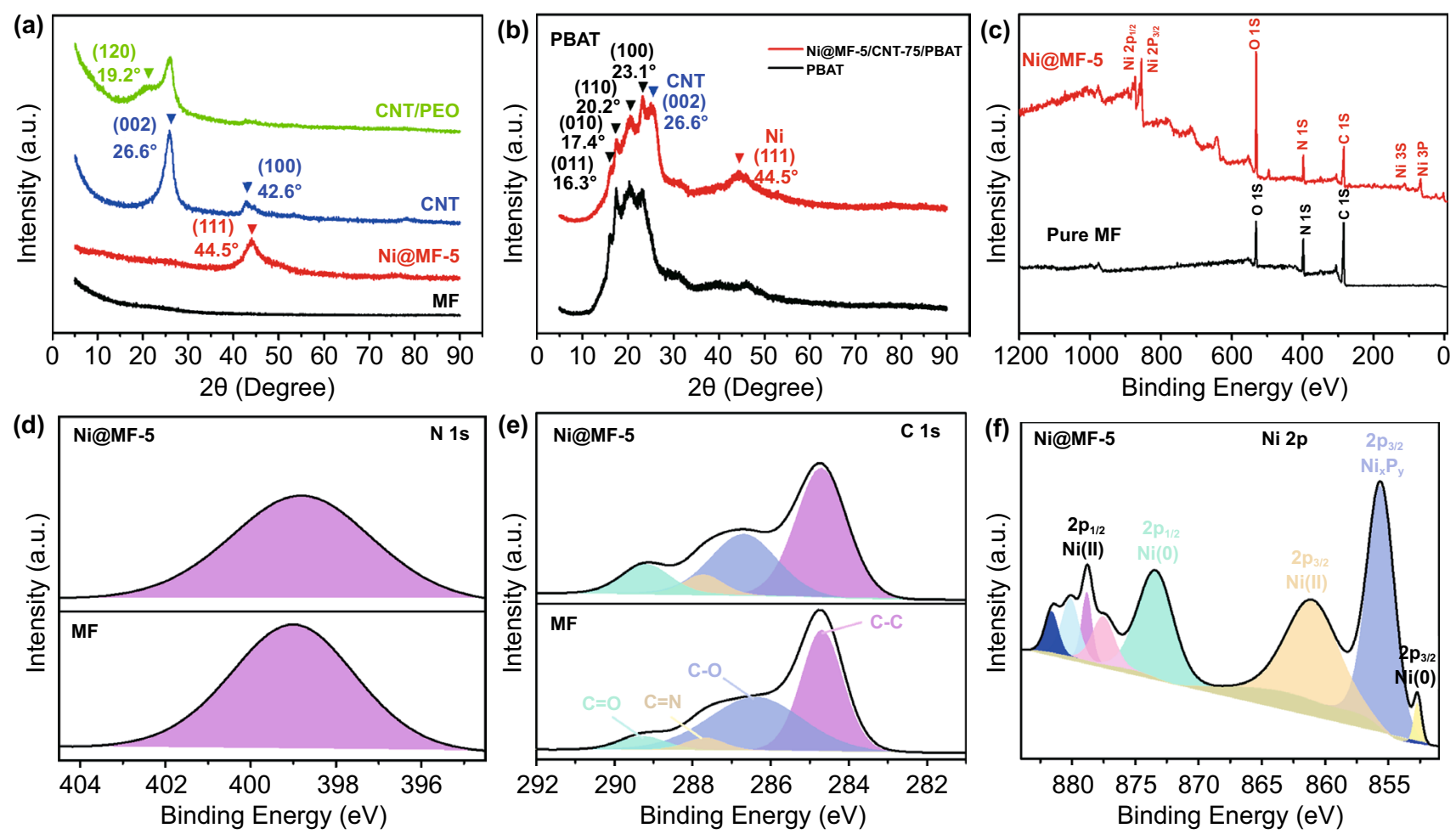

Fig. 2 Structure characterization of samples. a XRD patterns of MF, Ni@MF-5, CNT, and CNT/PEO. b XRD patterns of PBAT and Ni@ MF-5/CNT-75/PBAT. c Full-range XPS spectra of MF and Ni@MF-5. d Narrow N 1 s core-level XPS spectra of MF and Ni@MF-5. e Narrow C 1 s core-level XPS spectra of MF and Ni@MF-5. f Narrow Ni 2p core-level XPS spectrum of Ni@MF-5

$861.2 \mathrm{eV}$ are corresponding to $\mathrm{Ni}^{2+}$ in the form of $\mathrm{NiO}$ and $\mathrm{Ni}(\mathrm{OH})_{2}$, due to the introduction of oxygen groups during the deposition process and/or the surface oxidation of $\mathrm{Ni}$ nanoparticles by air. The sharp $\mathrm{Ni} 2 \mathrm{p}_{3 / 2}$ component at $855.7 \mathrm{eV}$ is assigned to $\mathrm{Ni}_{\mathrm{x}} \mathrm{P}_{\mathrm{y}}$, which means that $\mathrm{Ni}$ and $\mathrm{P}$ participate in the form of $\mathrm{Ni}-\mathrm{P}$ compounds in the plating procedure [52-54]. On the basis of these results, it can be concluded that Ni nanoparticles are successfully coated on the MF sponges.

\subsection{Directional EMI Shielding}

Generally, the electrical conductivity of materials is of great relevance to the EMI shielding performance [16, 42, 55]. It can be proved that the electrical conductivity of Ni@MF foams is enormously elevated from 28.6 to $460.8 \mathrm{~S} \mathrm{~m}^{-1}$, with the plating time extending from 1 to $5 \mathrm{~min}$ (Fig. S10a). All the CNT papers exhibit excellent electrical conductivity on the magnitude of $10^{3} \mathrm{~S} \mathrm{~m}^{-1}$ (Fig. S10b), owing to the continuous conductive networks built by the entangled and connected CNTs. Although the bottom electrical conductivity of Ni@MF/CNT/PBAT composites is evidently decreased after the encapsulation because of the poor conductivity of PBAT matrix, the bottom electrical conductivity is yet satisfactory with the highest value of $469.6 \mathrm{~S} \mathrm{~m}^{-1}$ for Ni@MF-3/ CNT-100/PBAT, which far surpasses the basic requirement $\left(1 \mathrm{~S} \mathrm{~m}^{-1}\right)$ for practical applications of conductive EMI shielding materials (Fig. S11) [56]. However, the top surfaces of $\mathrm{Ni} @ \mathrm{MF} / \mathrm{CNT} / \mathrm{PBAT}$ composites are electrically insulating $\left(<10^{-8} \mathrm{~S} \mathrm{~m}^{-1}\right)$, due to the physical isolation of PBAT. Thus, the top and bottom surfaces of $\mathrm{Ni@MF/CNT/PBAT} \mathrm{compos-}$ ites display the distinct electrical conductivity, which is in accordance with the structures from SEM images.

As expected from the superb electrical conductivity and step-wise asymmetry, Ni@MF/CNT/PBAT composites exhibit the unprecedented directional EMI shielding performance. Experiments " 1 " and "2" indicate that the EM wave is incident from $\mathrm{Ni} @ \mathrm{MF}$ layer and CNT layer, respectively (Fig. 3a, b). Regardless of the different incident directions, the EMI SE $\mathrm{T}_{\mathrm{T}}$ of all the composite samples 
reveals weak frequency dependence over the whole X-band (Fig. 3c, f). In addition, the EMI $\mathrm{SE}_{\mathrm{T}}$ values are significantly enhanced with the increasing plating time, following a parallel tendency to the varying electrical conductivity. MF/CNT-75/PBAT displays the lowest EMI $\mathrm{SE}_{\mathrm{T}}$ around $20 \mathrm{~dB}$ and the similar values $\left(\mathrm{SE}_{\mathrm{T} 1}\right.$ and $\left.\mathrm{SE}_{\mathrm{T} 2}\right)$ at different incident directions of the EM wave (Figs. 3c, f and $4 \mathrm{a}$ ). The
EMI shielding performance of MF/CNT-75/PBAT mainly stems from the conductive CNT layer, due to the insulating pure MF. The EMI SE $\mathrm{T}_{1}$ of Ni@MF-5/CNT-75/PBAT is enhanced up to the optimal value of $38.3 \mathrm{~dB}$, when the EM wave is incident from Ni@MF-5 layer (Fig. 4a). Strikingly, the EMT SE $\mathrm{T}_{2}$ of Ni@MF-5/CNT-75/PBAT with the incident EM wave from CNT layer is only $29.5 \mathrm{~dB}$, which (a)

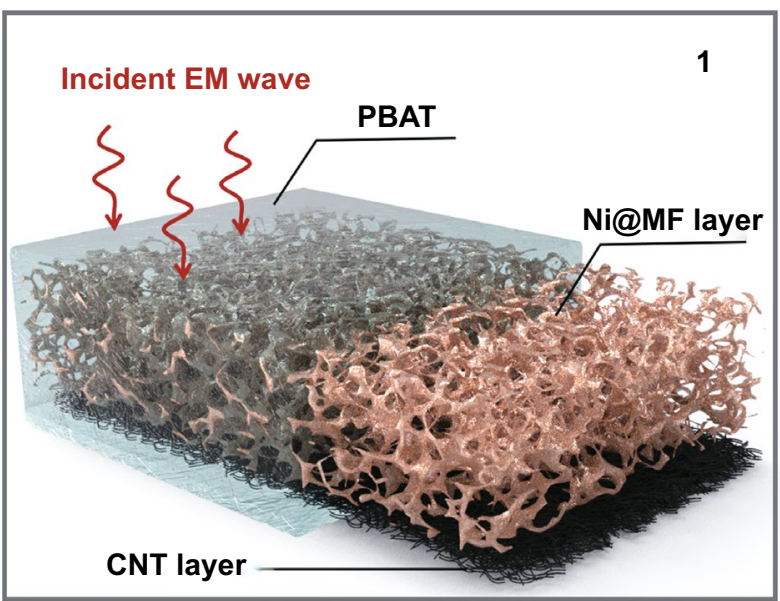

(b)

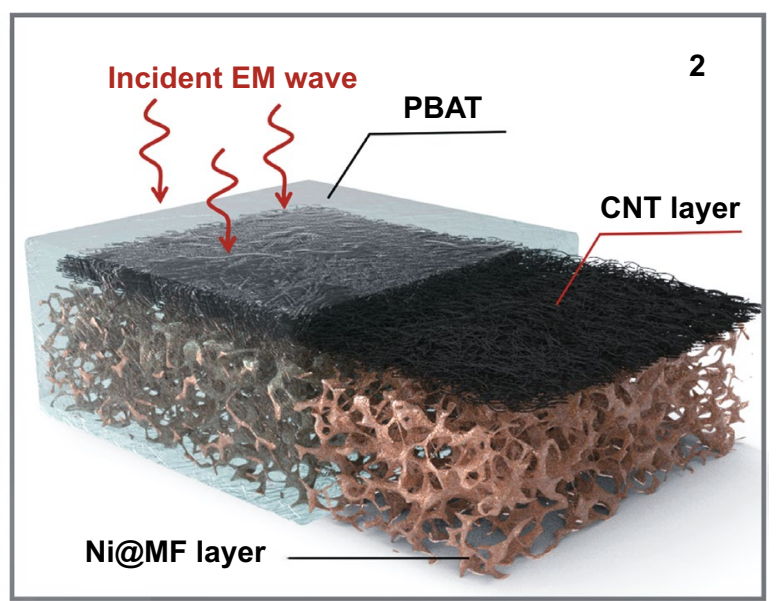

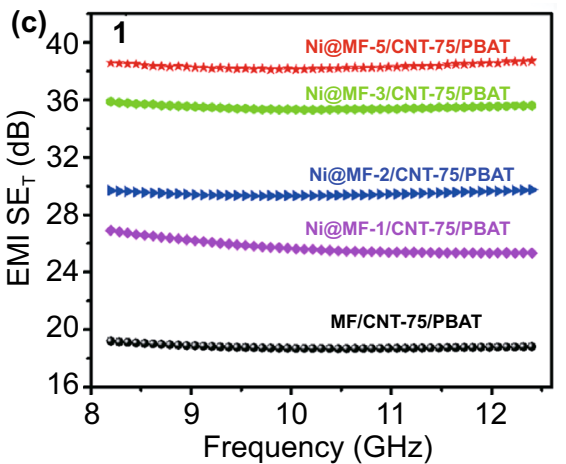
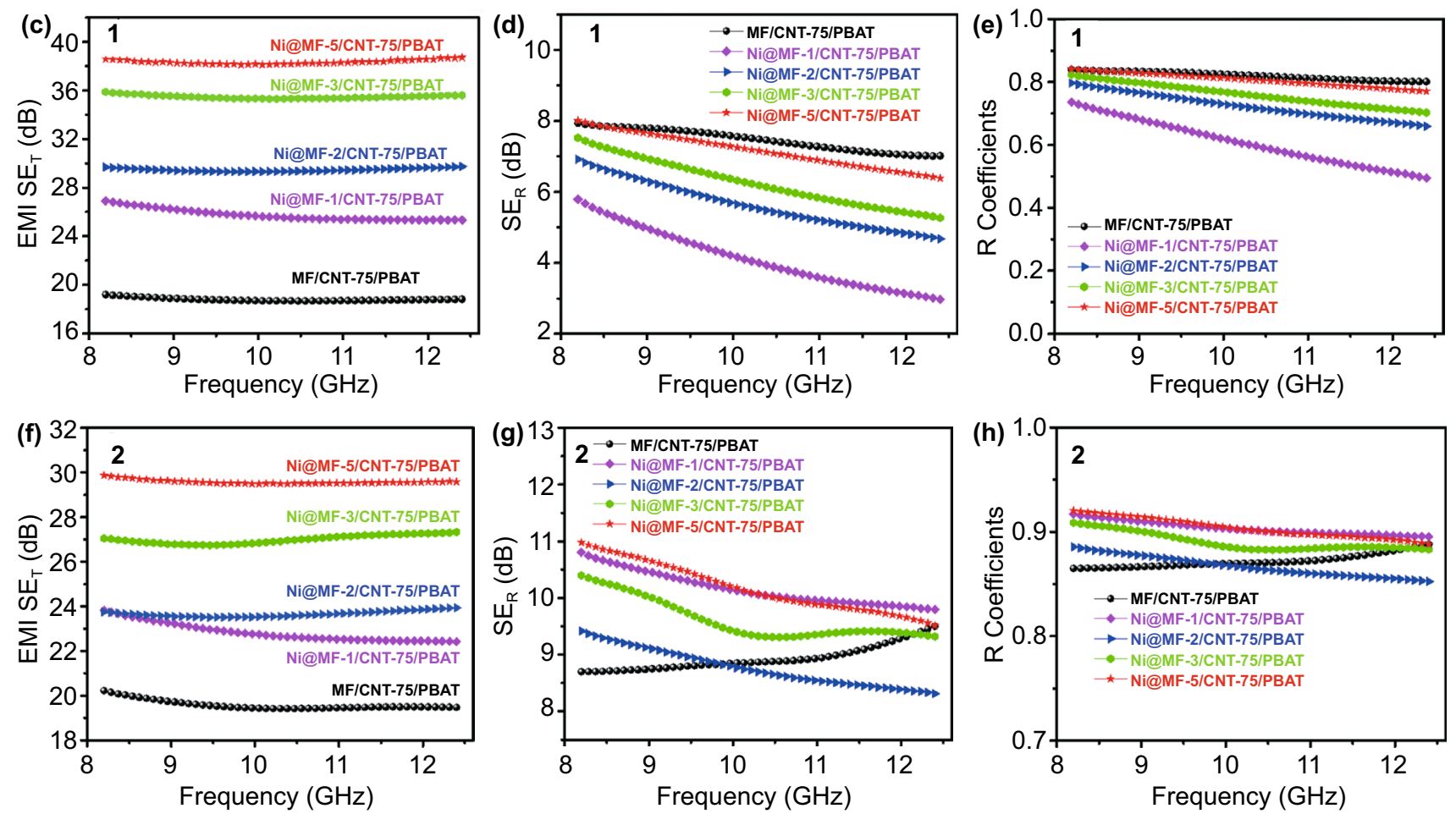

Fig. 3 Directional EMI shielding performances. a Schematic for experiment 1, the incident EM wave from Ni@MF layer. b Schematic for

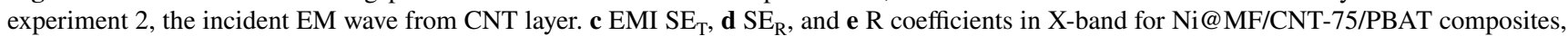

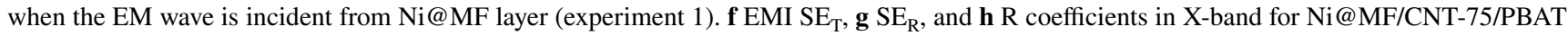
composites, when the EM wave is incident from CNT layer (experiment 2) 

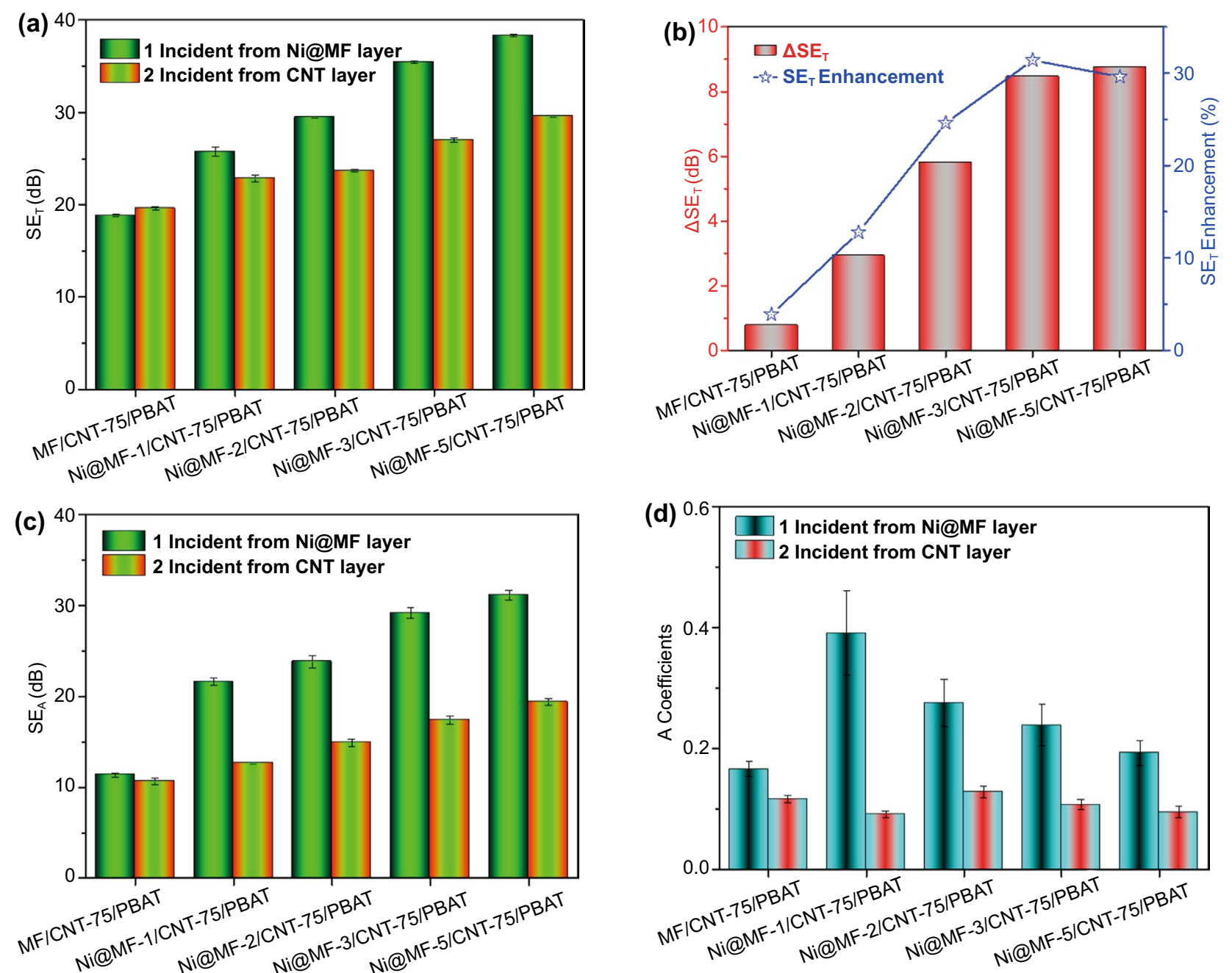

(e)

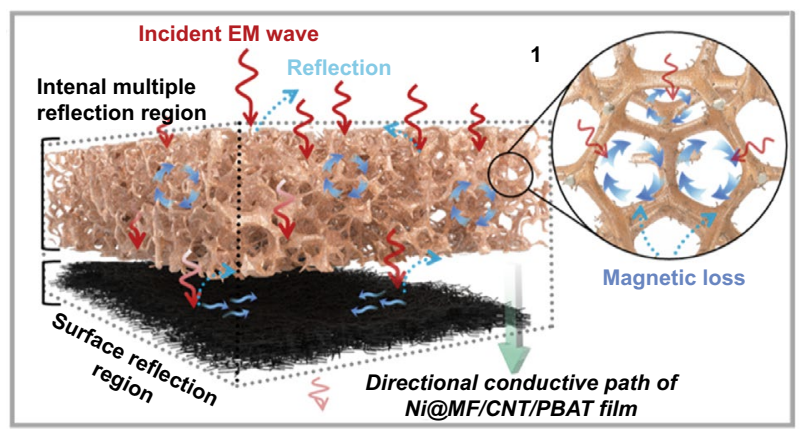

(f)

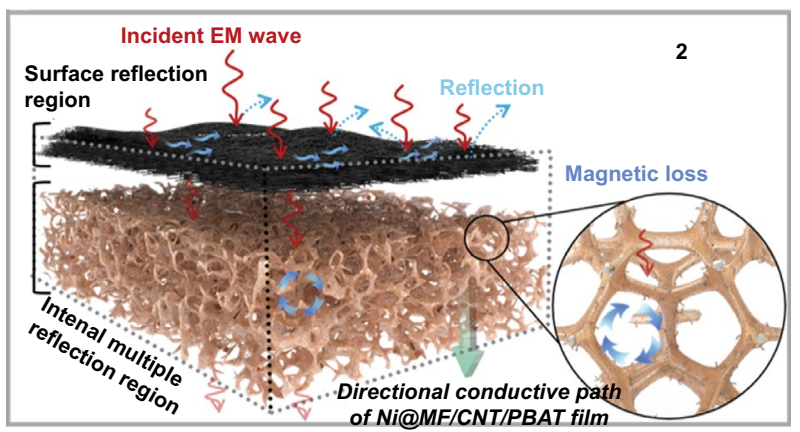

Fig. 4 Directional EMI shielding mechanism. a The average $\mathrm{SE}_{\mathrm{T}}$ of $\mathrm{Ni} @ \mathrm{MF} / \mathrm{CNT}-75 / \mathrm{PBAT}$ composites with the incident EM wave from different sample sides. b $\Delta \mathrm{SE}_{\mathrm{T}}$ and $\mathrm{SE}_{\mathrm{T}}$ enhancement of $\mathrm{Ni} @ \mathrm{MF} / \mathrm{CNT}-75 / \mathrm{PBAT}$ composites when the EM wave is incident from different sample sides. $\mathbf{c}$ The average $\mathrm{SE}_{\mathrm{A}}$ and $\mathbf{d}$ coefficients of Ni@MF/CNT-75/PBAT composites with the incident EM wave from different sample sides. e, $\mathbf{f}$ Schematic diagram of the directional EMI shielding mechanism for step-wise asymmetric Ni@MF/CNT-75/PBAT composites

is much lower than the EMI $\mathrm{SE}_{\mathrm{T} 1}$. Furthermore, Ni@MF-5/ CNT-75/PBAT exhibits $\Delta \mathrm{SE}_{\mathrm{T}}$ of $8.8 \mathrm{~dB}$ and SE enhancement of $30 \%$, indicating the novel directional EMI shielding property (Fig. 4b).
To theoretically clarify the directional EMI shielding mechanism of step-wise asymmetric Ni@MF/CNT-75/ PBAT composites, the absorption $\mathrm{SE}\left(\mathrm{SE}_{\mathrm{A}}\right)$, reflection $\mathrm{SE}$ $\left(\mathrm{SE}_{\mathrm{R}}\right)$, reflectivity power coefficient $(\mathrm{R})$, and absorptivity 
power coefficient (A) were calculated according to Eqs. (1-6). It is obviously seen that the largest $\mathrm{SE}_{\mathrm{R} 1}$ and $\mathrm{R}_{1}$ are both obtained for MF/CNT-75/PBAT, when the EM wave is incident from Ni@MF layer (Fig.3d, e). Since pure MF layer is almost transparent to EM wave, a majority of incident EM wave passes through MF layer with little attenuation. Then, a large part of EM wave is reflected back at the MFCNT layer interface owing to their impedance mismatch, which is closely related to the existence of plentiful mobile charge carriers in conductive CNT networks. For Ni@MF/ CNT-75/PBAT composites, both $\mathrm{SE}_{\mathrm{R} 1}$ and $\mathrm{R}_{1}$ illustrate the visually ascending tendency with the incremental plating time, which is in accord with the impedance mismatch theory [57]. Particularly, the $\mathrm{SE}_{\mathrm{R} 1}$ and $\mathrm{R}_{1}$ values of $\mathrm{Ni} @ \mathrm{MF}-5 /$ CNT-75/PBAT composite are $7.2 \mathrm{~dB}$ and 0.81 , respectively (Fig. S12). At the incident EM wave from CNT-75 layer, the $\mathrm{SE}_{\mathrm{R} 2}$ and $\mathrm{R}_{2}$ of $\mathrm{Ni} @ \mathrm{MF} / \mathrm{CNT}$-75/PBAT composites display the inapparent and irregular variation with the extending plating time (Figs. 3g, h, and S12). When the EM wave comes across the CNT-75 layer, enormous reflection immediately occurs due to the impedance mismatch between air and the conductive CNT layer, which mainly determines the $\mathrm{SE}_{\mathrm{R} 2}$ and $\mathrm{R}_{2}$ values. Thus, the $\mathrm{SE}_{\mathrm{R} 2}$ and $\mathrm{R}_{2}$ values of $\mathrm{Ni@}$ MF/CNT-75/PBAT composites have little dependence on the plating time. Comparatively, $\mathrm{SE}_{\mathrm{R} 2}$ and $\mathrm{R}_{2}$ are clearly higher than $\mathrm{SE}_{\mathrm{R} 1}$ and $\mathrm{R}_{1}$, respectively, for the identical Ni@ MF/CNT-75/PBAT composite, which is ascribed to the far higher electrical conductivity of bottom CNT layer than that of top Ni@MF layer. Detailedly, the $\Delta \mathrm{SE}_{\mathrm{R}}$ and $\mathrm{SE}_{\mathrm{R}}$ decrease of Ni@MF-1/CNT-75/PBAT is as high as $6.1 \mathrm{~dB}$ and 59\%, respectively, which are the maximum values of $\mathrm{Ni@MF/}$ CNT-75/PBAT composites (Fig. S13).

At different incident directions, both $\mathrm{SE}_{\mathrm{A} 1}$ and $\mathrm{SE}_{\mathrm{A} 2}$ of Ni@MF/CNT-75/PBAT composites are significantly prompted after prolonging the plating time, which is attributed to the increasing magnetic Ni particles and dissipative moving charge carriers (Fig. S14). $\mathrm{A}_{1}$ reveals an inverse change tendency to $R_{1}$ with the incremental plating time (Fig. S15a). Apparently, Ni@MF-1/CNT-75/PBAT displays the maximum $\mathrm{A}_{1}$ of 0.39 but the minimum $\mathrm{R}_{1}$ of 0.61 among the Ni@MF/CNT-75/PBAT composites (Fig. 4d). Like $\mathrm{R}_{2}$, $\mathrm{A}_{2}$ exhibits stable fluctuation with the varying plating time, on account of the superb electrical conductivity of CNT75 layer (Figs. $4 \mathrm{~d}$ and $\mathrm{S} 15 \mathrm{~b}$ ). In addition, $\mathrm{SE}_{\mathrm{A} 1}$ and $\mathrm{A}_{1}$ are absolutely superior to $\mathrm{SE}_{\mathrm{A} 2}$ and $\mathrm{A}_{2}$, respectively, for a single $\mathrm{Ni} @$ MF/CNT-75/PBAT sample (Fig. 4c, d), which illuminates that the step-wise asymmetric structure plays a crucial role in manipulating not only the total EMI SE but also the contributions from reflection and absorption. For example, Ni@MF-5/CNT-75/PBAT possesses the high $\mathrm{SE}_{\mathrm{A} 1}$ of $31.2 \mathrm{~dB}$ and the low $\mathrm{SE}_{\mathrm{A} 2}$ of $19.4 \mathrm{~dB}\left(\Delta \mathrm{SE}_{\mathrm{A}}=11.8 \mathrm{~dB}\right.$ and $\mathrm{SE}_{\mathrm{A}}$ enhancement $=61 \%$, Fig. S16). Thus, in comparison with $\mathrm{SE}_{\mathrm{T} 2}$, the $\mathrm{SE}_{\mathrm{T} 1}$ enhancement is primarily ascribed to the enormous improvement of microwave absorption.

To better make sense of the directional shielding mechanism, the EM wave transfer across step-wise asymmetric Ni@MF/CNT-75/PBAT composites at different incident directions is schematically illustrated in Fig. 4e, f. No matter which side of Ni@MF/CNT-75/PBAT composites EM wave is incident from, $\mathrm{R}$ is always higher than $\mathrm{A}$, indicating the dominant role of EM reflection in the EMI shielding process. This phenomenon is mainly ascribed to the fact that a large part of EM wave is reflected by the material surface before penetrating it [42]. When the EM wave is incident from Ni@ MF layer, some incident EM wave passes into Ni@ MF layer with relatively weak reflectivity due to the low electrical conductivity of Ni@MF layer (Fig. 4e). The entered EM wave is trapped in the porous Ni@MF sponge and intensively interacts with the high-density charge carriers. Consequently, a large part of EM wave is absorbed via magnetic and dielectric losses [58]. Furthermore, the multiple reflection of EM wave in pores can prolong the propagation path to promote the absorption or dissipation of EM wave [59]. As the penetrated EM wave encounters the high conductive layer of CNT-75, most of the remaining EM wave is reflected back into the porous Ni@MF layer, due to the large impedance mismatch between Ni@MF and CNT-75 layers. The reflected EM wave is highly absorbed again via the above-mentioned magnetic loss, dielectric loss, and multiple reflection in porous $\mathrm{Ni@}$ $\mathrm{MF}$ sponge, thus effectively raising the $\mathrm{SE}_{\mathrm{A} 1}$ value. A spot of reflected EM wave will ultimately propagate back into space after the dissipation in Ni@MF sponge, which is able to offset the weak reflection $\left(\mathrm{SE}_{\mathrm{R} 1}\right)$ to some extent. Afterward, the EM wave entered CNT-75 layer is further attenuated, owing to interacting with free charge carriers in the conductive networks. The reasonable step-wise asymmetric structures give rise to "weak reflection-absorption-strong reflection-reabsorption" mechanism when EM wave is incident from the 
$\mathrm{Ni@MF} \mathrm{layer.} \mathrm{In} \mathrm{this} \mathrm{manner,} \mathrm{the} \mathrm{composites} \mathrm{exhibit} \mathrm{won-}$ derful EMI SE against the EM wave. At the incident direction from CNT-75 layer, the high conductive CNT layer directly reflects a large portion of the incident EM wave before allowing it to enter, by reason of the great impedance mismatch (Fig. 4f). Hence, the subsequent absorption in porous $\mathrm{Ni@}$ MF sponge is largely reduced. Additionally, the second reflection at the interface between $\mathrm{Ni@MF} \mathrm{layer} \mathrm{and} \mathrm{air} \mathrm{is}$ too weak to evidently contribute to the total EMI shielding, because of the low electrical conductivity of $\mathrm{Ni} @ \mathrm{MF}$ layer. It can be proved that the EM incident from CNT-75 layer encounters the "strong reflection-absorption" process, and thus, the energy loss is obviously lower than that incident from Ni@MF layer. We can draw a conclusion that stepwise asymmetric Ni@MF/CNT-75/PBAT composites exhibit unprecedented directional EMI shielding performances and may open up a new research direction for EMI shielding materials.

So as to evaluate the effect of CNT thickness, the EMI shielding performances of Ni@MF-3/CNT/PBAT composites with various $\mathrm{CNT}$ thickness were systemically characterized (Figs. S17-S19). The incident direction of EM wave is from the Ni@MF-3 layer. It is easily found that $\mathrm{SE}_{\mathrm{T}}$ of $\mathrm{Ni@MF-3/CNT/PBAT} \mathrm{composites} \mathrm{is} \mathrm{enhanced} \mathrm{with} \mathrm{the}$ incremental thickness of CNT paper, which is independent from frequency. Note that the $\mathrm{SE}_{\mathrm{T}}$ value is clearly raised from 19.9 dB for Ni@MF-3/PBAT to 35.9 dB for Ni@ MF-3/CNT-100/PBAT. The $\mathrm{SE}_{\mathrm{A}}$ of Ni@MF-3/CNT/PBAT composites also exhibits the rising trend with the increase of CNT thickness, whereas $\mathrm{SE}_{\mathrm{R}}$ of the composites shows no obvious variation. This illustrates that the enhancement of $\mathrm{SE}_{\mathrm{T}}$ is mainly stemming from the improved microwave absorption. The $\mathrm{SE}_{\mathrm{A}}$ and $\mathrm{SE}_{\mathrm{R}}$ of Ni@MF-3/CNT-100/PBAT are 30.4 and $5.5 \mathrm{~dB}$, respectively. Furthermore, the A coefficient continuously increases, but the R coefficient slightly decreases, as the thickness of CNT paper is elevated. Ni@ MF-3/CNT-100/PBAT exhibits the largest A of 0.28 and lowest $\mathrm{R}$ of 0.72 . This exciting phenomenon can be ascribed to the rational step-wise asymmetric structures. The thicker CNT layer with higher conductivity (Fig. S11) can reflect more incident EM back into porous Ni@MF layer where the reflected EM can be further reabsorbed or dissipated in the form of heat via magnetic loss and dielectric loss [60]. As a result, the step-wise asymmetric Ni@MF/CNT/PBAT composites have great potential for efficient EMI shielding in portable and intelligent electronics.

\subsection{Practical Application for Directional EMI Shielding}

As highly effective EMI shielding materials, fantastic mechanical performances are also of great significance for the practical application, especially in the fields of portable and wearable electronic devices. Herein, tensile measurements were conducted to explore the mechanical properties of Ni@MF/CNT-75/PBAT composites. The typical stress-strain curves of Ni@MF/CNT-75/PBAT composites reveal that all the composites are fractured in a ductile manner with satisfactory strain, by reason of the flexible PBAT chains, which is vital for enduring mechanical deformation (Fig. 5a). Specially, pure PBAT exhibits a tensile strength of $9.5 \mathrm{MPa}$, a toughness of $6.2 \mathrm{MJ} \mathrm{m}^{-3}$, a Young's modulus of $33.2 \mathrm{MPa}$, and a fracture strain of $80.1 \%$ (Figs. 5b and S20, S21). With the introduction of rigid MF, the tensile strength and Young's modulus of the MF/CNT-75/PBAT composite are significantly enhanced to 12.8 and $44.2 \mathrm{MPa}$, respectively, due to the excellent strengthening effect of MF. Correspondingly, the reduced toughness of $4.3 \mathrm{MJ} \mathrm{m}^{-3}$ and strain at break of $50.1 \%$ are achieved for MF/CNT-75/PBAT composite. Besides, all the crucial tensile properties regarding tensile strength, toughness, Young's modulus, and fracture strain of Ni@MF/CNT-75/PBAT composites are deteriorated with the increasing plating time. The most probable reason is that the rough Ni nanoparticles decorated on MF sponge induce more defect (void) and stress concentration points that require less energy to propagate the cracks. Fortunately, Ni@MF/CNT-75/PBAT composites yet present the acceptable mechanical properties for the actual application in portable microelectronics.

In order to intuitionally illustrate the novel directional EMI shielding performances of step-wise asymmetric Ni@MF/ CNT/PBAT composites, a real application test was conducted using a remote controlled toy car system consisting of a motor module, indicator module, transmitter module, and receiver module (Fig. 5c-e and Video S1). The signal transmitter with a functional voltage of $3 \mathrm{~V}$ sends the signal microwave that can be received by the receiving module. Then, the indicator lights are flashed, and the motor is brought into operation 

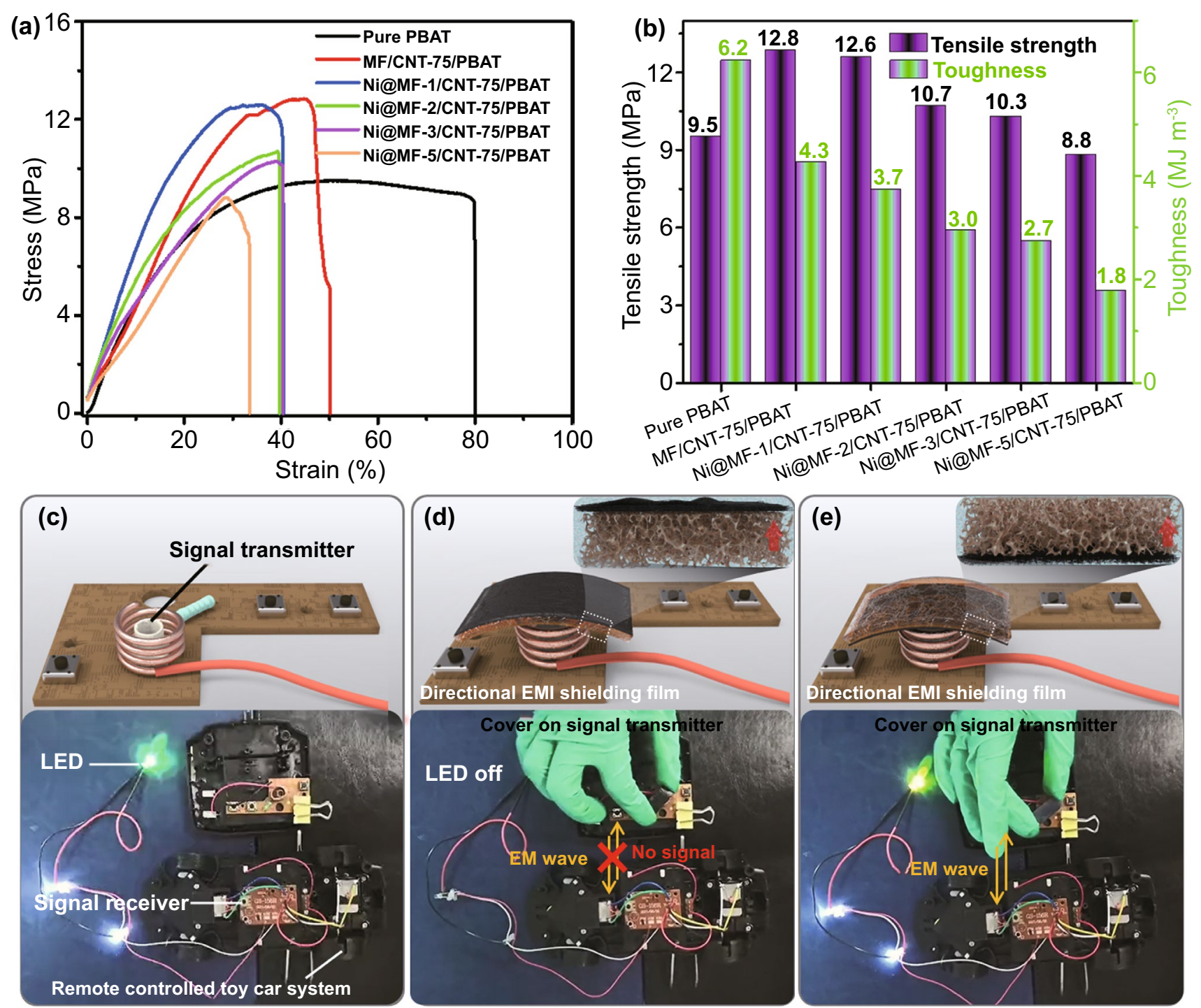

Fig. 5 Practical application for directional EMI shielding. a Typical stress-strain curves of pure PBAT and step-wise asymmetric Ni@MF/ CNT-75/PBAT composites with different Ni-plating times. b The corresponding tensile strength and toughness. C-e A real directional EMI shielding application measurement in a remote controlled toy car system. The signal transmitter is faced with $\mathbf{c}$ no shielding material, $\mathbf{d} \mathrm{Ni} @ \mathrm{MF}$ layer, and e CNT-75 layer of the Ni@MF-5/CNT-75/PBAT composite

(Fig. 5c and Video S1). When the signal transmitter is faced with the Ni@MF layer of Ni@MF-5/CNT-75/PBAT, that is, the EM is incident from $\mathrm{Ni@MF} \mathrm{layer} \mathrm{into} \mathrm{the} \mathrm{composite,}$ the indicator lights are switched off and the motor stops running (Fig. 5d). This is attributed to the fact that the signal microwave is efficiently blocked by Ni@MF-5/CNT-75/PBAT with the incident direction from $\mathrm{Ni@MF} \mathrm{layer.} \mathrm{However,} \mathrm{the}$ indicator lights are able to be turn on again and the motor also is set into motion by turning over the step-wise asymmetric Ni@MF-5/CNT-75/PBAT, where the signal microwave is incident from the CNT-75 layer. This interesting phenomenon can provide a new strategy for designing the step-wise asymmetric shielding composites in the creative field of directional EMI shielding.

\section{Conclusions}

In this work, we successfully designed step-wise asymmetric conductive networks to fabricate the novel directional EMI shielding composite materials. Ni@MF sponges were obtained by a facile electroless plating process, and 
CNT papers were prepared via a simple vacuum-assisted self-assembly approach. Then, solution encapsulation was applied to fabricate Ni@MF/CNT/PBAT composites with step-wise asymmetric structures. Ni@MF/CNT/ PBAT composites display the distinctly asymmetric electrical conductivity on the top and bottom surfaces, in good agreement with the structure analysis from SEM images. As expected from the superb electrical conductivity and step-wise asymmetric structures, Ni@MF/CNT/PBAT composites exhibit the extraordinary directional EMI shielding performance. When the EM wave is incident from Ni@MF layer, the EMI SE $\mathrm{T}_{1}$ of Ni@MF-5/CNT$75 /$ PBAT is elevated up to the optimal value of $38.3 \mathrm{~dB}$ with the prolonged plating time. Strikingly, at the incident EM wave from CNT paper, the EMT SE $\mathrm{T}_{2}$ of $\mathrm{Ni} @ \mathrm{MF}-5 /$ CNT-75/PBAT is only $29.5 \mathrm{~dB}$, showcasing the obvious $\Delta \mathrm{SE}_{\mathrm{T}}$ of $8.8 \mathrm{~dB}$ and $\mathrm{SE}$ enhancement of $30 \%$. The reasonable step-wise asymmetric structures consisting of loose $\mathrm{Ni@MF} \mathrm{and} \mathrm{compact} \mathrm{CNT} \mathrm{layers} \mathrm{can} \mathrm{produce} \mathrm{a} \mathrm{special}$ "weak reflection-absorption-strong reflection-reabsorption” course for the incident EM wave from Ni@MF layer. In a practical directional EMI shielding application, $\mathrm{Ni@}$ MF-5/CNT-75/PBAT composite is proved to efficiently block the signal microwave transmission, when the signal microwave is incident from Ni@MF layer. If turning over Ni@MF-5/CNT-75/PBAT composite, the remote controlled toy car system is brought into operation once again, which demonstrates the directional EMI shielding of Ni@MF/CNT/PBAT composites in actual applications. This investigation provides a significant insight into the construct and fabrication of step-wise asymmetric polymeric composites with novel directional EMI shielding properties for the enormous prospect in portable electronics and communication industry.

\section{Supporting Information}

SEM images of pure MF, Ni@MF, and Ni@MF/CNT/ PBAT composites; Ni percentage in Ni@MF; The thickness of CNT/PBAT layer in Ni@MF-3/CNT/PBAT composites; The magnified XRD pattern of PBAT in $10-30^{\circ}$; Resistance and conductivity of $\mathrm{Ni} @ \mathrm{MF}, \mathrm{CNT}$ paper, and $\mathrm{Ni@MF/CNT/PBAT} \mathrm{composites;} \mathrm{EMI} \mathrm{shielding} \mathrm{properties}$ of Ni@MF/CNT/PBAT composites; Young's modulus and fracture strain of Ni@MF/CNT-75/PBAT composites.

Acknowledgements Science and Technology Plan Project of Guizhou Province (No. [2019]1084 and [2018]5781); National Natural Science Foundation of China (No. 51963003); The Youth Science and Technology Talent Growth Project of Guizhou Province Education Department (No. [2018]106); Outstanding Youth Program of Guizhou Province (No. 20170439178); The Key project of Fundamental research in Guizhou province [2020]1Z044; and Scientific Research Project of Introduced Talents of Guizhou University (No. (2017)07) are acknowledged for the financial support.

Funding Open access funding provided by Shanghai Jiao Tong University.

Open Access This article is licensed under a Creative Commons Attribution 4.0 International License, which permits use, sharing, adaptation, distribution and reproduction in any medium or format, as long as you give appropriate credit to the original author(s) and the source, provide a link to the Creative Commons licence, and indicate if changes were made. The images or other third party material in this article are included in the article's Creative Commons licence, unless indicated otherwise in a credit line to the material. If material is not included in the article's Creative Commons licence and your intended use is not permitted by statutory regulation or exceeds the permitted use, you will need to obtain permission directly from the copyright holder. To view a copy of this licence, visit http://creativecommons.org/licenses/by/4.0/.

Supplementary Information The online version contains supplementary material available at https://doi.org/10.1007/ s40820-021-00743-y.

\section{References}

1. H. Abbasi, M. Antunes, J.I. Velasco, Recent advances in carbon-based polymer nanocomposites for electromagnetic interference shielding. Prog. Mater. Sci. 103, 319-373 (2019). https://doi.org/10.1016/j.pmatsci.2019.02.003

2. B. Yao, W. Hong, T.W. Chen, Z.B. Han, X.W. Xu et al., Highly stretchable polymer composite with strain-enhanced electromagnetic interference shielding effectiveness. Adv. Mater. 32(14), 1907499 (2020). https://doi.org/10.1002/ adma.201907499

3. B. Fu, P. Ren, Z. Guo, Y. Du, Y. Jin et al., Construction of three-dimensional interconnected graphene nanosheet network in thermoplastic polyurethane with highly efficient electromagnetic interference shielding. Compos. B Eng. 215, 108813 (2021). https://doi.org/10.1016/j.compositesb. 2021.108813 
4. J. Guo, H.X. Song, H. Liu, C.J. Luo, Y.R. Ren et al., Polypyrrole-interface-functionalized nano-magnetite epoxy nanocomposites as electromagnetic wave absorbers with enhanced flame retardancy. J. Mater. Chem. C 5(22), 5334-5344 (2017). https://doi.org/10.1039/C7TC01502J

5. Z. Guo, P. Ren, Z. Zhang, Z. Dai, K. Hui et al., Simultaneous realization of highly efficient electromagnetic interference shielding and human motion detection in carbon fiber felt decorated with silver nanowires and thermoplastic polyurethane. J. Mater. Chem. C 9(21), 6894-6903 (2021). https:// doi.org/10.1039/D1TC01099A

6. D.H. Yu, Y. Liao, Y.C. Song, S.L. Wang, H.Y. Wan et al., Conductive materials: a super-stretchable liquid metal foamed elastomer for tunable control of electromagnetic waves and thermal transport. Adv Sci 7(12), 2070064 (2020). https://doi.org/10.1002/advs.202070064

7. D. Micheli, A. Vricella, R. Pastore, M. Marchetti, Synthesis and electromagnetic characterization of frequency selective radar absorbing materials using carbon nanopowders. Carbon 77, 756-774 (2014). https://doi.org/10.1016/j.carbon. 2014.05.080

8. X.Y. Liu, X.X. Jin, L. Li, J.F. Wang, Y.Y. Yang et al., Airpermeable, multifunctional, dual-energy driven MXenedecorated polymeric textile-based wearable heaters with exceptional electrothermal and photothermal conversion performance. J. Mater. Chem. A 8(25), 12526-12537 (2020). https://doi.org/10.1039/D0TA03048A

9. A. Iqba, F. Shahzad, K. Hantanasirisaku, M.K. Kim, J. Kwon et al., Anomalous absorption of electromagnetic waves by $2 \mathrm{D}$ transition metal carbonitride $\mathrm{Ti}_{3} \mathrm{CNT}_{\mathrm{x}}(\mathrm{MXene})$. Science 369(6502), 446-450 (2020). https://doi.org/10.1126/science. aba7977

10. A. Charles, A.N. Rider, S.A. Brown, C.H. Wang, Multifunctional magneto-polymer matrix composites for electromagnetic interference suppression, sensors and actuators. Prog. Mater. Sci. 115, 100705 (2021). https://doi.org/10.1016/j. pmatsci.2020.100705

11. Y.Z. Zhang, J.K. El-Demellawi, Q. Jiang, G. Ge, H.F. Liang et al., MXene hydrogels: fundamentals and applications. Chem. Soc. Rev. 49(20), 7229-7251 (2020). https://doi.org/ 10.1039/D0CS00022A

12. L.X. Liu, W. Chen, H.B. Zhang, Q.W. Wang, F.L. Guan et al., Flexible and multifunctional silk textiles with biomimetic leaf-like MXene/silver nanowire Nanostructures for electromagnetic interference shielding, humidity monitoring, and self-derived hydrophobicity. Adv. Funct. Mater. 29(44), 1905197 (2019). https://doi.org/10.1002/adfm. 201905197

13. Z. Barani, F. Kargar, Y. Ghafouri, S. Ghosh, K. Godziszewski et al., Electrically insulating flexible films with quasi-1D van der Waals fillers as efficient electromagnetic shields in the $\mathrm{GHz}$ and sub-THz frequency bands. Adv. Mater. 33(11), 2007286 (2021). https://doi.org/10.1002/adma.202007286

14. Y.M. Chen, L. Zhang, Y. Yang, B. Pang, W.H. Xu et al., Recent progress on nanocellulose aerogels: preparation, modification, composite fabrication, applications. Adv. Mater. 33(11), 2005569 (2021). https://doi.org/10.1002/adma.20200 5569

15. D.W. Jiang, V. Murugadoss, Y. Wang, J. Lin, T. Ding et al., Electromagnetic interference shielding polymers and nanocomposites-a review. Polym. Rev. 59(2), 280-337 (2019). https://doi.org/10.1080/15583724.2018.1546737

16. C.B. Liang, K.P. Ruan, Y.L. Zhang, J.W. Gu, Multifunctional flexible electromagnetic interference shielding silver nanowires/cellulose films with excellent thermal management and joule heating performances. ACS Appl. Mater. Interfaces 12(15), 18023-18031 (2020). https://doi.org/10.1021/acsami. 0c04482

17. Z.L. Ma, S.L. Kang, J.Z. Ma, L. Shao, Y.L. Zhang et al., Ultraflexible and mechanically strong double layered aramid nanofiber- $\mathrm{Ti}_{3} \mathrm{C}_{2} \mathrm{~T}_{\mathrm{x}} \mathrm{MXene/silver}$ nanowire nanocomposite papers for high-performance electromagnetic interference shielding. ACS Nano 14(7), 8368-8382 (2020). https://doi. org/10.1021/acsnano.0c02401

18. B. Zhou, Z. Zhang, Y.L. Li, G.J. Han, Y.Z. Feng et al., Flexible, robust, and multifunctional electromagnetic interference shielding film with alternating cellulose nanofiber and MXene layers. ACS Appl. Mater. Interfaces 12(4), 4895-4905 (2020). https://doi.org/10.1021/acsami.9b19768

19. D.X. Yan, H. Pang, B. Li, R. Vajtai, L. Xu et al., Structured reduced graphene oxide/polymer composites for ultra-efficient electromagnetic interference shielding. Adv. Funct. Mater. 25(4), 559-566 (2015). https://doi.org/10.1002/adfm.20140 3809

20. H.L. Fu, Z.P. Yang, Y.Y. Zhang, M. Zhu, Y.H. Jia et al., SWCNT-modulated folding-resistant sandwich-structured graphene film for high-performance electromagnetic interference shielding. Carbon 162, 490-496 (2020). https://doi.org/ 10.1016/j.carbon.2020.02.081

21. H.L. Yang, Z. Yu, P. Wu, H.W. Zou, P.B. Liu, Electromagnetic interference shielding effectiveness of microcellular polyimide/in situ thermally reduced graphene oxide/carbon nanotubes nanocomposites. Appl. Surf. Sci. 434, 318-325 (2018). https:// doi.org/10.1016/j.apsusc.2017.10.191

22. B. Shen, Y. Li, D. Yi, W.T. Zhai, X.C. Wei et al., Microcellular graphene foam for improved broadband electromagnetic interference shielding. Carbon 102, 154-160 (2016). https:// doi.org/10.1016/j.carbon.2016.02.040

23. Z.H. Lin, J. Liu, W. Peng, Y.Y. Zhu, Y. Zhao et al., Highly stable 3D $\mathrm{Ti}_{3} \mathrm{C}_{2} \mathrm{~T}_{\mathrm{x}}$ MXene-based foam architectures toward high-performance terahertz radiation shielding. ACS Nano 14(2), 2109-2117 (2020). https://doi.org/10.1021/acsnano. $9 \mathrm{~b} 08832$

24. H.Y. Wu, L.C. Jia, D.X. Yan, J.F. Gao, X.P. Zhang et al., Simultaneously improved electromagnetic interference shielding and mechanical performance of segregated carbon nanotube/polypropylene composite via solid phase molding. Compos. Sci. Technol. 156, 87-94 (2018). https://doi.org/10. 1016/j.compscitech.2017.12.027 
25. Z.M. Fan, D.L. Wang, Y. Yuan, Y.S. Wang, Z.J. Cheng et al., A lightweight and conductive MXene/graphene hybrid foam for superior electromagnetic interference shielding. Chem. Eng. J. 381, 122696 (2020). https://doi.org/10.1016/j.cej.2019. 122696

26. W.Y. Wang, X. Ma, Y.W. Shao, X.D. Qi, J.H. Yang et al., Flexible, multifunctional, and thermally conductive nylon/ graphene nanoplatelet composite papers with excellent EMI shielding performance, improved hydrophobicity and flame resistance. J. Mater. Chem. A 9(8), 5033-5044 (2021). https:// doi.org/10.1039/D0TA11040J

27. Y.Y. Zhu, J. Liu, T. Guo, J.J. Wang, X.Z. Tang et al., Multifunctional $\mathrm{Ti}_{3} \mathrm{C}_{2} \mathrm{~T}_{\mathrm{x}}$ MXene composite hydrogels with strain sensitivity toward absorption-dominated electromagnetic interference shielding. ACS Nano 15(1), 1465-1474 (2021). https://doi.org/10.1021/acsnano.0c08830

28. M.C. Vu, P.J. Park, S.R. Bae, S.Y. Kim, Y.M. Kang et al., Scalable ultrarobust thermoconductive nonflammable bioinspired papers of graphene nanoplatelet crosslinked aramid nanofibers for thermal management and electromagnetic shielding. J. Mater. Chem. A 9(13), 8527-8540 (2021). https://doi.org/10. 1039/D0TA12306D

29. W. Zhai, C.F. Wang, S. Wang, J.N. Li, Y. Zhao et al., Ultrastretchable and multifunctional wearable electronics for superior electromagnetic interference shielding, electrical therapy and biomotion monitoring. J. Mater. Chem. A 9(11), 72387247 (2021). https://doi.org/10.1039/D0TA10991F

30. Y.H. Zhan, J. Wang, K.Y. Zhang, Y.C. Li, Y.Y. Meng et al., Fabrication of a flexible electromagnetic interference shielding $\mathrm{Fe}_{3} \mathrm{O}_{4} @$ reduced graphene oxide/natural rubber composite with segregated network. Chem. Eng. J. 344, 184-193 (2018). https://doi.org/10.1016/j.cej.2018.03.085

31. K. Wu, C.X. Lei, R. Huang, W.X. Yang, S.G. Chai et al., Design preparation of a unique segregated double network with excellent thermal conductive property. ACS Appl. Mater. Interfaces 9(8), 7637-7647 (2017). https://doi.org/10.1021/ acsami.6b16586

32. S.Y. Li, X.Y. Li, C.C. Chen, H.Y. Wang, Q.Y. Deng et al., Development of electrically conductive nano bamboo charcoal/ultra-high molecular weight polyethylene composites with a segregated network. Compos. Sci. Technol. 132, 31-37 (2016). https://doi.org/10.1016/j.compscitech.2016.06.010

33. Y. Jin, R.A. Gerhardt, Prediction of the percolation threshold and electrical conductivity of self-assembled antimony-doped tin oxide nanoparticles into ordered structures in PMMA/ATO nanocomposites. ACS Appl. Mater. Interfaces 6(24), 22264 22271 (2014). https://doi.org/10.1021/am5061239

34. B.W. Yu, Z.Y. Zhao, S.R. Fu, L. Meng, Y.H. Liu et al., Fabrication of PLA/CNC/CNT conductive composites for high electromagnetic interference shielding based on pickering emulsions method. Compos. Part A Appl. Sci. Manuf. 125, 105558 (2019). https://doi.org/10.1016/j.compositesa.2019. 105558

35. W.C. Yu, T. Wang, Y.H. Liu, Z.G. Wang, L. Xu et al., Superior and highly absorbed electromagnetic interference shielding performance achieved by designing the reflection-absorption-integrated shielding compartment with conductive wall and lossy core. Chem. Eng. J. 393, 124644 (2020). https://doi.org/10.1016/j.cej.2020.124644

36. R.J. Bian, G.L. He, W.Q. Zhi, S.L. Xiang, T.W. Wang et al., Ultralight MXene-based aerogels with high electromagnetic interference shielding performance. J. Mater. Chem. C 7(3), 474-478 (2019). https://doi.org/10.1039/C8TC04795B

37. A.K. Singh, A. Shishkin, T. Koppel, N. Gupta, A review of porous lightweight composite materials for electromagnetic interference shielding. Compos. B Eng. 149, 188-197 (2018). https://doi.org/10.1016/j.compositesb.2018.05.027

38. J. Liu, H.B. Zhang, R.H. Sun, Y.F. Liu, Z.S. Liu et al., Hydrophobic, flexible, and lightweight MXene foams for high-performance electromagnetic interference shielding. Adv. Mater. 29(38), 1702367 (2017). https://doi.org/10. 1002/adma.201702367

39. H.L. Xu, X.W. Yin, X.L. Li, M.H. Li, S. Liang et al., Lightweight $\mathrm{Ti}_{3} \mathrm{C}_{2} \mathrm{~T}_{\mathrm{x}}$ MXene/poly(vinyl alcohol) composite foams for electromagnetic wave shielding with absorption-dominated feature. ACS Appl. Mater. Interfaces 11(10), 1019810207 (2019). https://doi.org/10.1021/acsami.8b21671

40. C.B. Liang, H. Qiu, P. Song, X.T. Shi, J. Kong et al., Ultralight MXene aerogel/wood-derived porous carbon composites with wall-like "mortar/brick" structures for electromagnetic interference shielding. Sci. Bull. 65(8), 616-622 (2020). https://doi.org/10.1016/j.scib.2020.02.009

41. Q.W. Wei, S.F. Pei, X.T. Qian, H.P. Liu, Z.B. Liu et al., Superhigh electromagnetic interference shielding of ultrathin aligned pristine graphene nanosheets film. Adv. Mater. 32(14), 1907411 (2020). https://doi.org/10.1002/ adma.201907411

42. Y. Li, B. Xue, S.D. Yang, Z.L. Cheng, L. Xie et al., Flexible multilayered films consisting of alternating nanofibrillated cellulose $/ \mathrm{Fe}_{3} \mathrm{O}_{4}$ and carbon nanotube/polyethylene oxide layers for electromagnetic interference shielding. Chem. Eng. J. 410, 128356 (2021). https://doi.org/10.1016/j.cej.2020.128356

43. F. Shahzad, M. Alhabeb, C.B. Hatter, B. Anasori, S. Man Hong et al., Electromagnetic interference shielding with 2D transition metal carbides (MXenes). Science 353(6304), 1137-1140 (2016). https://doi.org/10.1126/science.aag2421

44. L. Li, Y.X. Cao, X.Y. Liu, J.F. Wang, Y.Y. Yang et al., Multifunctional MXene-based fireproof electromagnetic shielding films with exceptional anisotropic heat dissipation capability and joule heating performance. ACS Appl. Mater. Interfaces 12(24), 27350-27360 (2020). https://doi.org/10.1021/ acsami.0c05692

45. C.X. Lei, Y.Z. Zhang, D.Y. Liu, K. Wu, Q. Fu, Metal-level robust, folding endurance, and highly temperature stable MXene-based film with engineered aramid nanofiber for extreme-condition electromagnetic interference shielding applications. ACS Appl. Mater. Interfaces 12(23), 2648526495 (2020). https://doi.org/10.1021/acsami.0c07387

46. Y. Zhang, W.H. Cheng, W.X. Tian, J.Y. Lu, L. Song et al., Nacre-inspired tunable electromagnetic interference shielding sandwich films with superior mechanical and fire-resistant 
protective performance. ACS Appl. Mater. Interfaces 12(5), 6371-6382 (2020). https://doi.org/10.1021/acsami.9b18750

47. Y.D. Xu, Y.Q. Yang, D.X. Yan, H.J. Duan, G.Z. Zhao et al., Gradient structure design of flexible waterborne polyurethane conductive films for ultraefficient electromagnetic shielding with low reflection characteristic. ACS Appl. Mater. Interfaces 10(22), 19143-19152 (2018). https://doi. org/10.1021/acsami.8b05129

48. A. Sheng, W. Ren, Y.Q. Yang, D.X. Yan, H.J. Duan et al., Multilayer WPU conductive composites with controllable electro-magnetic gradient for absorption-dominated electromagnetic interference shielding. Compos. Part A Appl. Sci. Manuf. 129, 105692 (2020). https://doi.org/10.1016/j.compo sitesa.2019.105692

49. H.J. Duan, H.X. Zhu, J.F. Gao, D.X. Yan, K. Dai et al., Asymmetric conductive polymer composite foam for absorption dominated ultra-efficient electromagnetic interference shielding with extremely low reflection characteristics. J. Mater. Chem. A 8(18), 9146-9159 (2020). https://doi.org/10.1039/ D0TA01393E

50. I. Gupta, N.H. Tai, Carbon materials and their composites for electromagnetic interference shielding effectiveness in X-band. Carbon 152, 159-187 (2019). https://doi.org/10. 1016/j.carbon.2019.06.002

51. L.Q. Zhang, B. Yang, J. Teng, J. Lei, D.X. Yan et al., Tunable electromagnetic interference shielding effectiveness via multilayer assembly of regenerated cellulose as a supporting substrate and carbon nanotubes/polymer as a functional layer. J. Mater. Chem. C 5(12), 3130-3138 (2017). https://doi.org/ 10.1039/C6TC05516H

52. L.Y. Liang, G.J. Han, Y. Li, B. Zhao, B. Zhou et al., Promising $\mathrm{Ti}_{3} \mathrm{C}_{2} \mathrm{~T}_{\mathrm{x}}$ MXene/Ni chain hybrid with excellent electromagnetic wave absorption and shielding capacity. ACS Appl. Mater. Interfaces 11(28), 25399-25409 (2019). https://doi.org/ 10.1021/acsami.9b07294

53. B.Y. Wen, X.J. Wang, Y. Zhang, Ultrathin and anisotropic polyvinyl butyral/Ni-graphite/short-cut carbon fibre film with high electromagnetic shielding performance. Compos.
Sci. Technol. 169, 127-134 (2019). https://doi.org/10.1016/j. compscitech.2018.11.013

54. J.B. Park, H. Rho, A.N. Cha, H. Bae, S.H. Lee et al., Transparent carbon nanotube web structures with $\mathrm{Ni}-\mathrm{Pd}$ nanoparticles for electromagnetic interference (EMI) shielding of advanced display devices. Appl. Surf. Sci. 516, 145745 (2020). https:// doi.org/10.1016/j.apsusc.2020.145745

55. P. Zhang, X. Ding, Y.Y. Wang, Y. Gong, K. Zheng, Segregated double network enabled effective electromagnetic shielding composites with extraordinary electrical insulation and thermal conductivity. Compos. Part A Appl. Sci. Manuf. 117, 56-64 (2019). https://doi.org/10.1016/j.compositesa.2018. 11.007

56. C. Wang, V. Murugadoss, J. Kong, Z.F. He, X.M. Mai et al., Overview of carbon nanostructures and nanocomposites for electromagnetic wave shielding. Carbon 140, 696-733 (2018). https://doi.org/10.1016/j.carbon.2018.09.006

57. J. Cao, Z.H. Zhou, Q.C. Song, K.Y. Chen, G.H. Su et al., Ultrarobust $\mathrm{Ti}_{3} \mathrm{C}_{2} \mathrm{~T}_{\mathrm{x}}$ MXene-based soft actuators via bambooinspired mesoscale assembly of hybrid nanostructures. ACS Nano 14(6), 7055-7065 (2020). https://doi.org/10.1021/acsna no.0c01779

58. C. Xiang, R.H. Guo, S.J. Lin, S.X. Jiang, J.W. Lan et al., Lightweight and ultrathin $\mathrm{TiO}_{2}-\mathrm{Ti}_{3} \mathrm{C}_{2} \mathrm{~T}_{\mathrm{X}}$ /graphene film with electromagnetic interference shielding. Chem. Eng. J. 360, 1158-1166 (2019). https://doi.org/10.1016/j.cej.2018.10.174

59. X.X. Zhou, Y. Wang, C.C. Gong, B. Liu, G. Wei, Production, structural design, functional control, and broad applications of carbon nanofiber-based nanomaterials: a comprehensive review. Chem. Eng. J. 402, 126189 (2020). https://doi.org/10. 1016/j.cej.2020.126189

60. Y. Li, B. Shen, D. Yi, L.H. Zhang, W.T. Zhai et al., The influence of gradient and sandwich configurations on the electromagnetic interference shielding performance of multilayered thermoplastic polyurethane/graphene composite foams. Compos. Sci. Technol. 138, 209-216 (2017). https://doi.org/10. 1016/j.compscitech.2016.12.002 